\title{
Molecular Neurobiology \\ Melatonin prevents the harmful effects of obesity on the brain, including at the behavioral level \\ --Manuscript Draft--
}

\begin{tabular}{|c|c|}
\hline Manuscript Number: & MOLN-D-17-00610R1 \\
\hline Article Type: & Original Article \\
\hline Keywords: & leptin deficiency, obesity, brain, brain damage, melatonin, aggresome \\
\hline Corresponding Author: & $\begin{array}{l}\text { Adrian Rubio-González } \\
\text { Universidad de Oviedo } \\
\text { SPAIN }\end{array}$ \\
\hline First Author: & Adrian Rubio-González \\
\hline \multirow[t]{10}{*}{ Order of Authors: } & Adrian Rubio-González \\
\hline & Juan Carlos Bermejo-Millo \\
\hline & Beatriz de Luxán-Delgado \\
\hline & Yaiza Potes \\
\hline & Zulema Pérez-Martínez \\
\hline & José Antonio Boga \\
\hline & Ignacio Vega-Naredo \\
\hline & Beatriz Caballero \\
\hline & Juan José Solano \\
\hline & Ana Coto-Montes \\
\hline Abstract: & $\begin{array}{l}\text { Obesity is a health problem caused by a diet rich in energy and the sedentary lifestyle } \\
\text { of modern societies. A leptin deficiency is one of the worst causes of obesity, since it } \\
\text { results in morbid obesity, a chronic disease without a cure. Leptin is an adipokine } \\
\text { secreted in a manner dependent on the circadian rhythm that ultimately reduces food } \\
\text { intake. We studied cellular alterations in brain of leptin-deficient obese animals and } \\
\text { tested whether these alterations are reflected in abnormal behaviors. Obesity induced } \\
\text { increases in oxidative stress and the unfolded protein response caused by } \\
\text { endoplasmic reticulum stress. However, the subsequent signaling cascade was } \\
\text { disrupted, blocking possible systemic improvements and increasing the production of } \\
\text { misfolded proteins, that trigger autophagy. Up-regulated autophagy was not indefinitely } \\
\text { maintained and misfolded proteins accumulated in obese animals, which led to } \\
\text { aggresome formation. Finally, neurodegenerative markers together with anxiety and } \\
\text { stress-induced behaviors were observed in leptin-deficient mice. As oxidative stress } \\
\text { has an essential role in the development of these harmful effects of obesity, melatonin, } \\
\text { a powerful antioxidant, might counteract these effects on the brain. Following treatment } \\
\text { with melatonin, the animals' antioxidant defenses were improved and misfolded } \\
\text { protein, proteasome activity and autophagy decreased. Aggresome formation was } \\
\text { reduced due to the reduction in the levels of misfolded proteins and the reduction in } \\
\text { tubulin expression, a key element in aggresome development. The levels of } \\
\text { neurodegenerative markers were reduced and the behaviors recovered. The data } \\
\text { support the use of melatonin in therapeutic interventions to reduce brain damage } \\
\text { induced by leptin deficiency-dependent obesity. }\end{array}$ \\
\hline
\end{tabular}


leptin deficiency, obesity, brain, brain damage, melatonin, aggresome. José Solano ${ }^{3 a}$, Ana Coto-Montes ${ }^{1 a *}$ Clavería s/n, 33006, Oviedo, Principado de Asturias, Spain. Principado de Asturias, Spain. Principado de Asturias, Spain.

${ }^{a}$ Members of Research Team cROS (cellular Response to Oxidative Stress).

\section{*Corresponding author}

Ana Coto Montes Clavería, s/n, 33006, Oviedo, Principado de Asturias, Spain

Phone:

Fax:

E-mail:

\section{MELATONIN PREVENTS THE HARMFUL EFFECTS OF OBESITY} ON THE BRAIN, INCLUDING AT THE BEHAVIORAL LEVEL

Adrian Rubio-González ${ }^{\text {la }}$, Juan Carlos Bermejo-Millo ${ }^{\text {la }}$, Beatriz de Luxán-Delgado ${ }^{\text {la }}$, Yaiza Potes ${ }^{1 a}$, Zulema Pérez-Martínez ${ }^{2 a}$, José Antonio Boga ${ }^{2 a}$, Ignacio Vega-Naredo ${ }^{\text {la }}$, Beatriz Caballero ${ }^{\text {1a, }}$, Juan

${ }^{1}$ Department of Morphology and Cell Biology, Faculty of Medicine, University of Oviedo, Avda. Julián

${ }^{2}$ Microbiology Service, Hospital Universitario Central de Asturias, Avda. Roma, s/n, 33011, Oviedo,

${ }^{3}$ Geriatrics Service, Hospital Monte Naranco, Avda. Doctores Fernández Vega, 107, 33012, Oviedo,

Department of Morphology and Cell Biology, Faculty of Medicine, University of Oviedo, Avda. Julián 


\section{Abstract}

28 Obesity is a health problem caused by a diet rich in energy and the sedentary lifestyle of modern societies. A leptin deficiency is one of the worst causes of obesity, since it results in morbid obesity, a chronic disease without a cure. Leptin is an adipokine secreted in a manner dependent on the circadian rhythm that ultimately reduces food intake. We studied cellular alterations in brain of leptin-deficient obese animals and tested whether these alterations are reflected in abnormal behaviors. Obesity induced increases in oxidative stress and the unfolded protein response caused by endoplasmic reticulum stress. However, the subsequent signaling cascade was disrupted, blocking possible systemic improvements and increasing the production of misfolded proteins, that trigger autophagy. Up-regulated autophagy was not indefinitely maintained and misfolded proteins accumulated in obese animals, which led to aggresome formation. Finally, neurodegenerative markers together with anxiety and stress-induced behaviors were observed in leptin-deficient mice. As oxidative stress has an essential role in the development of these harmful effects of obesity, melatonin, a powerful antioxidant, might counteract these effects on the brain. Following treatment with melatonin, the animals' antioxidant defenses were improved and misfolded protein, proteasome activity and autophagy decreased. Aggresome formation was reduced due to the reduction in the levels of misfolded proteins and the reduction in tubulin expression, a key element in aggresome development. The levels of neurodegenerative markers were reduced and the behaviors recovered. The data support the use of melatonin in therapeutic interventions to reduce brain damage induced by leptin deficiency-dependent obesity. 


\section{Introduction}

The prevalence of the overweight and obesity epidemics have significantly increased in the last three decades, including a dramatic rise in the prevalence of both disorders among adolescents. Currently, $39 \%$ of the global population is overweight and $13 \%$ is obese [1]. Overweight and obesity are the fifth leading causes of death worldwide; therefore, obesity and its associated health problems urgently require new strategies for effective treatments.

Obesity is a risk factor for many diseases such as diabetes, musculoskeletal disorders, some cancers, renal pathologies and, primarily cardiovascular diseases [2]. In addition, central nervous system damage induced by obesity has recently been reported $[3,4]$. According to animal studies, high-energy diet damages the structure and function of the hippocampus [5]. The brain is particularly susceptible to oxidative stress due to its high glucose and oxygen consumption [6], which generates a large amount of reactive oxygen species (ROS), and its poor antioxidant defense system [7].

Oxidative stress damages macromolecules and ultimately leads to dysfunctional neurons. Thus, cells (particularly postmitotic cells such as neurons) contain quality control mechanisms such as the unfolded protein response (UPR), proteasome and autophagy to remove damaged proteins [8]. When unfolded/misfolded proteins accumulate in the endoplasmic reticulum (ER), ER stress occurs and induces the UPR in order to decrease protein synthesis and increase the synthesis of chaperones and the activity of the ubiquitin/proteasome system $[9,10]$. If this response is not able to repair or avoid the accumulation of unfolded/misfolded proteins, the proteasome [11] and autophagy, particularly chaperone-mediated autophagy (CMA) and macroautophagy [12], are responsible for removing these proteins. Unfortunately, if these mechanisms fail, aggresomes begin to accumulate, hampering vesicle traffic. As shown in a recent publication by our group, autophagy is altered in the livers of obese individuals [13].

Obesity is caused by several factors, physiological to psychological conditions, and some unknown factors. However, leptin is one of the main factors, as a reduction in its levels or receptor inefficiency leads to morbid obesity $[14,15]$. 

8

Leptin, a $16 \mathrm{kDa}$ adipokine, is an anorexigenic peptide hormone synthesized in and secreted from peripheral adipocytes. Upon binding to its receptor within the hypothalamus, leptin induces a biochemical cascade that ultimately reduces food intake and increases energy expenditure. This peptide is secreted with circadian rhythmicity, with maximal production in the middle of the night [16]; thus, leptin is inevitably associated with melatonin.

Melatonin (N-acetyl-5-methoxytryptamine) is synthesized by the pineal gland and plays a fundamental role in the control of circadian rhythms [17]. In fact, its relation with leptin has been established. According to several studies, melatonin administration decreases plasma and serum leptin levels in rats [18-20]. Moreover, pinealectomy results in an increase in circulating leptin concentrations, whereas the circadian rhythm of leptin secretion remains unchanged [21]. In summary, melatonin administration reduces serum leptin concentrations in both pinealectomized and normal rats.

Melatonin has many other functions in addition to its Zeitgeber role. Melatonin is one of the best known natural antioxidants $[22,23]$. The high efficiency of melatonin as an antioxidant depends on its ability to easily cross cell membranes due to its amphipathic nature [12]. Melatonin is also implicated in changes in body weight, depending on the photoperiod [24]. This molecule promotes weight loss by stimulating non-shivering thermogenesis and the recruitment of brown fat in small mammals [25]. In addition, melatonin regulates many other aspects of body weight and adiposity, such as energy intake and expenditure, glucose uptake [26], the serum lipid profile, blood pressure and inflammation [27]. Numerous publications have confirmed the regulatory roles of melatonin in the cell cycle, apoptosis and autophagy $[12,17,28]$. These effects of melatonin have been poorly studied in relation to its influence on actions of leptin in the brain.

Based on these considerations, the present study thoroughly analyzes the neuronal and behavioral alterations in leptin-deficient mice and whether a melatonin treatment counteracts the negative effects. Leptin deficiency-induced obesity caused diverse forms of cellular damage and led to abnormal behaviors through a similar pathway to aging, which was partially prevented by the melatonin treatment.

\section{Materials and methods}




\section{Animals}

101 Sixteen six-week-old male wild-type mice (C57BL/6J) and sixteen six-week-old male leptin-deficient 102 obese B6.V-Lepob/J (ob/ob) mice were purchased from Charles River Laboratories (Barcelona, Spain).

103 The ob/ob mice are characterized by hyperphagia, massive obesity (these mice weigh up to four times

104 more than wild-type mice), transient hyperglycemia, and elevated plasma insulin concentrations (10-50

105 times higher than normal) [29]. This syndrome is inherited as a single autosomal recessive gene located 106 on chromosome 6 [29]. The mice were housed two per cage under a 12:12 hour dark:light cycle at $22 \pm$

$1072{ }^{\circ} \mathrm{C}$. The animals received tap water and a standard chow diet ad libitum. Higher food intake and the

108 subsequent increase in the body mass index of the ob/ob mice compared with wild-type animals were

109 reported previously [13].

110

111 Body and tissue parameters

112 All of the animals were weighed at the beginning (baseline) and end of the experiment (sacrifice) and 113 both brain and body weights were recorded.

\section{Melatonin treatment}

116 After a two-week acclimatization period, animals were randomly divided into four groups with eight 117 mice per group: the untreated control groups of wild-type and ob/ob mice (WC and ObC, respectively)

118 and the melatonin-treated groups of wild-type and ob/ob mice (WM and ObM, respectively).

119 Two hours after the lights were switched off, melatonin (Sigma-Aldrich, St. Louis, MO, USA) was 120 intraperitoneally injected at a dose of $500 \mu \mathrm{g} / \mathrm{kg}$ body weight daily for 4 weeks. Melatonin was dissolved 121 in $0.5 \%$ absolute ethanol:saline. Animals in the control groups received a comparable dose of vehicle 122 via the same route for the same treatment duration.

123 The animals were euthanized by decapitation, and the brain of each mouse was immediately removed,

124 flash-frozen in liquid nitrogen and stored at $-80{ }^{\circ} \mathrm{C}$ until further analysis. The experimental protocol was 125 approved by the Oviedo University Animal Care and Use Committee. All experiments were performed 
127 (Council Directive 86/609/EEC).

\section{Tissue processing}

130 The brain of each mouse was homogenized in buffer ( $\mathrm{pH} 7.5$ ) containing $50 \mathrm{mM}$ sodium phosphate

131 buffer, $100 \mathrm{mM} \mathrm{NaCl}, 1 \mathrm{mM} \mathrm{Na}_{3} \mathrm{VO}_{4}, 1 \mathrm{mM} \mathrm{NaF}$ and 1\% Triton at a ratio 1:10 (w:v) using an Ultra-

132 Turrax T25 Mixer (IKA, Staufen, Germany). The homogenates were centrifuged at $900 \mathrm{~g}$ for 6 minutes

133 at $4{ }^{\circ} \mathrm{C}$. Supernatants containing proteins were collected, aliquoted and frozen at $-80{ }^{\circ} \mathrm{C}$ until further 134 analysis.

136 Protein quantification

137 The Bradford method was used to quantify the protein concentrations in the brain homogenates [30].

\section{Oxidative damage}

\section{Protein oxidative damage}

141 Protein oxidative damage was determined by measuring the concentrations of carbonylated proteins 142 using the methods described by Levine et al. [31], with the modifications reported by Coto-Montes and 143 Hardeland [32]. The results are presented as nmol carbonylated protein/mg protein.

\section{Antioxidant enzyme activities}

\section{Total antioxidant activity}

147 Total antioxidant activity (TAA) was determined using the 2,2'-azino-bis(3-ethylbenzothiazoline-6148 sulphonic acid) (ABTS) cation radical method [33,34]. The results are expressed as mg equivalents

149 Trolox/mg protein.

$151 \quad$ Superoxide dismutase activity 
152 Superoxide dismutase (SOD; EC 1.15.1.1) activity was measured using the method reported by Martin 153 et al. [35]. This enzyme inhibits hematoxylin auto-oxidation to the colored compound hematein. The 154 results are expressed as SOD units/mg protein.

Catalase activity

157 Catalase (CAT; EC 1.11.1.6) activity was assayed using the method reported by Lubinsky and Bewley 158 [36] and $\mathrm{H}_{2} \mathrm{O}_{2}$ as the substrate. The results are expressed as $\mu m o l \mathrm{H}_{2} \mathrm{O}_{2} /$ mg protein*minute.

Glutathione peroxidase activity

161 Glutathione peroxidase (GPx; EC 1.11.1.9) catalyzes the reduction of $\mathrm{H}_{2} \mathrm{O}_{2}$ to $\mathrm{H}_{2} \mathrm{O}$ using the reducing 162 agent reduced glutathione (GSH), which is oxidized to glutathione (GSSG). The assay was performed 163 by monitoring the oxidation of NADPH [37]. The results are expressed as $\mu$ mol NADPH/mg 164 protein*minute.

Glutathione reductase activity

167 Glutathione reductase (GR; EC 1.6.4.2) activity was measured using the method described by Goldberg 168 and Spooner [38]. This enzyme catalyzes the reduction of oxidized glutathione (GSSG) to reduced 169 glutathione $(\mathrm{GSH})$ using $\mathrm{NADPH}+\mathrm{H}^{+}$as the substrate. The assay was performed by monitoring the 170 oxidation of NADPH [37]. The results are expressed as $\mu$ mol NADPH/mg protein*minute.

\section{Enzyme-linked immunosorbent assay (ELISA)}

173 Tumor necrosis factor $\alpha(T N F-\alpha)$

174 Brain levels of TNF- $\alpha$ were determined using a commercially available ELISA kit (KMC3011, 175 Invitrogen, Life Technologies, Thermo Fisher Scientific, Waltham, MA, USA). The assay was 176 performed according to the manufacturer's instructions, and the results are expressed as pg TNF- $\alpha / \mathrm{mg}$ 177 protein. 
180 Brain levels of IL-6 were determined using a commercially available ELISA kit (KMC0061, Novex,

181 Life Technologies, Thermo Fisher Scientific, Waltham, MA, USA). The assay was performed according

182 to the manufacturer's instructions. The results are expressed as pg IL-6/mg protein.

183

184

185

186

187

188

189

190

191

192

193

194

195

196

197

198

199

200

201

202

203

204

\section{S proteasome activity}

The activity of the $20 \mathrm{~S}$ proteasome was assessed using a $20 \mathrm{~S}$ proteasome activity assay kit (APT280, Chemicon, Merck Millipore, Billerica, MA, USA) based on the detection of the fluorophore 7-amino4-methylcoumarin (AMC) after its cleavage from the labeled substrate LLVY-AMC by the chymotrypsin-like activity of the proteasome. Free AMC was detected by fluorometric quantification (380/460 nm). The results are presented as $\mu \mathrm{M}$ AMC/mg protein.

\section{Western blot immunoassay}

Tissue homogenates (50 $\mu \mathrm{g}$ of protein per sample) were mixed with Laemmli sample buffer (Bio-Rad Laboratories, Inc., Hercules, CA, USA) and denatured by boiling at $100^{\circ} \mathrm{C}$ for 5 minutes. The samples were fractionated using sodium dodecyl sulfate polyacrylamide gel electrophoresis (SDS-PAGE) at 200 $\mathrm{V}$ and subsequently transferred onto a polyvinylidene fluoride (PVDF) membranes (Immobilon TM-P; Millipore Corp., Bedford, MA, USA) at $350 \mathrm{~mA}$.

The membranes were blocked with 5 or $10 \%(\mathrm{w} / \mathrm{v})$ nonfat dry milk dissolved in Tris-buffered saline

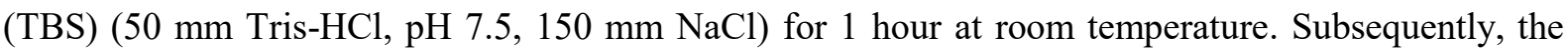
membranes were incubated with the following primary antibodies overnight at $4{ }^{\circ} \mathrm{C}$ : anti-IRE1 $\alpha(3294$, Cell Signaling Technology, Inc., Danvers, MA, USA), anti-phosphorylated-eIF2 $\alpha$ (3398, Cell Signaling Technology, Inc., Danvers, MA, USA), anti-ATF-6 $\alpha$ (sc-22799, Santa Cruz Biotechnology, Santa Cruz, CA, USA), anti-ubiquitin (3933, Cell Signaling Technology, Inc., Danvers, MA, USA), anti-LAMP2A (ab18528, Abcam, Cambridge, UK), anti-Beclin-1 (sc-10086, Santa Cruz Biotechnology, Santa Cruz, CA, USA), anti-LC3 (PD014, Medical \& Biological Laboratories CO., LTD., Naka-ku Nagoya, Japan), anti-p62 (H00008878-M01, Abnova, Walnut, CA, USA), anti- $\beta$-actin (AC-15, Sigma-Aldrich, St. 
Louis, MO, USA), anti- $\alpha$-tubulin (sc-23948, Santa Cruz Biotechnology, Santa Cruz, CA, USA), anti207 vimentin (5741, Cell Signaling Technology, Inc., Danvers, MA, USA), anti- $\beta$-amyloid (2454, Cell 208 Signaling Technology, Inc., Danvers, MA, USA), anti- $\alpha$-synuclein (2642, Cell Signaling Technology, Inc., Danvers, MA, USA), anti-Tau p-S ${ }^{199}$, anti-Tau p-T ${ }^{205}$, anti-Tau p-S ${ }^{396}$ and anti-Tau p-S ${ }^{404}(44779 \mathrm{G}$, Invitrogen, Life Technologies, Thermo Fisher Scientific, Waltham, MA, USA).The antibodies were 211 diluted in TBS buffer containing $1 \%(\mathrm{w} / \mathrm{v})$ nonfat dry milk and $0.02 \%$ sodium azide. After three 10 212 minutes washes in Tris-buffered saline containing Tween (TBS-T) (50 mm Tris/HCl, pH 7.5, $150 \mathrm{~mm}$ $213 \mathrm{NaCl}$, and $0.05 \%$ Tween-20), the membranes where incubated with the corresponding horseradish 214 peroxidase-conjugated secondary antibody (anti-goat (A4174, Sigma-Aldrich, St. Louis, MO, USA), anti-mouse (7076, Cell Signaling Technology, Inc., Danvers, MA, USA), anti-anti-rabbit (7074, Cell Signaling Technology, Inc., Danvers, MA, USA)) diluted in TBS buffer containing 1\% (w/v) nonfat dry milk for 1 hour at room temperature, followed by three 10 minutes washes in TBS-T.

218 The membranes were developed using a chemiluminescent substrate (WBKLS0500, Merck Millipore, 219 Billerica, MA, USA) according to the manufacturer's protocol. Protein levels were quantitated using 220 Image Studio Lite 5.2.5 software (LI-COR Biotechnology, Lincoln, NE, USA). Variations in the levels of the typical housekeeping proteins (GAPDH, $\beta$-actin and $\alpha$-tubulin) were found, so Ponceau S staining was used to ensure equal loading [39]. The results were expressed as percent change from the WC sample. Due to high LC3-I protein expression and low LC3-II protein expression, LC3-I signal overexposures covered the low LC3-II signal. Then, we have separately pictures of each protein, since the problem was always that both proteins needed different exposure times to get the best ones, again because of low LC3-II protein expression.

\section{Protein identification by peptide mass fingerprinting}

229 Brain protein homogenates $(15 \mu \mathrm{g})$ were mixed with Laemmli sample buffer (Bio-Rad Laboratories, 230 Inc., Hercules, CA, USA) and boiled at $100^{\circ} \mathrm{C}$ for 5 minutes to completely denature the proteins. Both 231 samples and prestained molecular weight standards (Precision Plus Protein All Blue Standards (Bio232 Rad Laboratories, Inc., Hercules, CA, USA)) were loaded onto 10\% SDS-PAGE gels. Gels were 233 electrophoresed at $100 \mathrm{~V}$, stained with a mixture of $30 \%(\mathrm{v}: \mathrm{v})$ methanol, $10 \%$ (v:v) acetic acid and 
235 destained using a mixture of $40 \%(\mathrm{v}: \mathrm{v})$ methanol and $10 \%(\mathrm{v}: \mathrm{v})$ acetic acid. Images of the stained gels 236 were captured using a GS-800 Imaging Densitometer (Bio-Rad Laboratories, Inc., Hercules, CA, USA) 237 and semiquantitatively analyzed using Image Studio Lite 5.2.5 software (LI-COR Biotechnology, 238 Lincoln, NE, USA). The results were expressed as percent change from the WC sample.

239 The bands of interest were processed according to the protocol described by Oliván et al. [40]. Bands 240 of interest were sent to the proteomics laboratory of Inbiotec S.L. (León, Spain) for identification, where 241 the proteins were digested according to the method reported by Havlis et al. [41] and processed for 242 further analysis using the method reported by Jami et al. [42].

243 Protein candidates produced by this combined peptide mass fingerprinting/tandem MS search were 244 considered valid when the global Mascot score was greater than 85 with a significance level of $p<0.05$.

\section{Porsolt Swim Test (PST)}

247 The PST developed by Porsolt in 1977 [43] is a model of behavioral hopelessness based on the induction 248 of immobility in animals in response to a stressful stimulus, and the results are interpreted as the animals' 249 susceptibility to negative moods.

250 The behavioral test was conducted in a designated behavior room to provide a suitably quiet 251 environment and the necessary equipment for behavioral assays. The animals were placed in a 252 transparent glass cylinder $(13 \mathrm{~cm}$ diameter $\mathrm{x} 24 \mathrm{~cm}$ high $)$, filled with $22 \pm 2{ }^{\circ} \mathrm{C}$ water. The animals were 253 subjected to a single-phase test for 4 minutes. Their behaviors were recorded and then designated as 254 either immobility or mobility. We have considered mobility as vigorous movements with the front 255 and/or back legs in and out of the water, as proposed by Gersner et al. [44]. Passive displacement was 256 considered as immobility. After each test, the mice were dried with a thermal blanket before being 257 returned to their accommodation cage.

\section{Statistical analysis}


All results are presented as the mean values \pm standard deviations (SD) of the means. All data presented representative data obtained from at least three separate experiments. The results were analyzed using two-way analysis of variance (ANOVA), with the first effect analyzing the phenotype (WC and ObC) and the second effect analyzing the treatment (WC and $\mathrm{ObC}$ or $\mathrm{WM}$ and $\mathrm{ObM}$ ), and differences between individual means were analyzed with the Bonferroni post hoc test. The differences were considered statistically significant when $p<0.05$. Statistical analyses were performed with GraphPad Prism 6 software (GraphPad Software, Inc., La Jolla, CA, USA).

\section{Results}

\section{Body and tissue parameters}

As shown in Table 1, body weight at sacrifice was higher in ob/ob mice than in wild-type mice $(p<0.001)$; however, the administration of melatonin did not produce changes in this parameter in either mouse strain. Interestingly, brain weight was significantly lower in ob/ob than in wild-type mice $(p<0.01)$, and the melatonin treatment slightly increased the brain weight in ob/ob animals to levels similar to the wild-type mice, although the difference was not significant (Table 1).

\section{Leptin-deficient mice exhibit greater oxidative damage in the brain}

277 Oxidative damage to proteins was evaluated by measuring the protein carbonyl content and the results 278 showed greater oxidative damage in brains from leptin-deficient (ob/ob) mice than in brains from wild279 type animals $(p<0.05)$. The melatonin treatment did not alter oxidative protein damage in wild-type 280 animals, but decreased protein carbonylation in ob/ob mice $(p<0.001)$ (Fig. 1a). We next measured the 281 levels of the main markers of the first line antioxidant defense system to elucidate the precise mechanism by which melatonin protected leptin-deficient mice.

283 The ABTS cation radical assay showed similar antioxidant capacities in the brains from both types of 284 mice. We only detected significant changes after the melatonin treatment, which was able to reduce 285 TAA levels in both strains ( $p<0.001$ for WC compared with WM and $p<0.01$ for ObC compared with $\mathrm{ObM}$ ), probably due to its well-described antioxidant properties (Fig. 1b). We measured the activities 
of the main antioxidant enzymes to complete the analysis. SOD and CAT activities were also similar in both types of mice. Melatonin slightly decreased SOD activity, whereas it significantly increased CAT activity in the brains from wild-type animals ( $p<0.01)$. Similarly, melatonin significantly decreased SOD activity and increased CAT activity in leptin-deficient mice $(p<0.05$ for SOD and $p<0.001$ for CAT) (Fig. 1c and d). GPx and GR activities also exhibited a similar pattern. Brains from ob/ob mice showed increased activities of both antioxidant enzymes compared with brains from wild-type animals $(p<0.05$ for GPx and $p<0.01$ for GR). Although the melatonin treatment induced a slight increase in GPx activity in wild-type animals, this increase was only significant in ob/ob mice $(p<0.01)$ (Fig. 1e). In contrast, the melatonin treatment was only able to significantly increase GR activity in the wild-type mice $(p<0.01)$ (Fig. 1f). In summary, the melatonin treatment induced a readjustment in the antioxidant system, improving the redox balance, particularly in ob/ob animals, by stimulating SOD, CAT and GPx activities.

\section{Leptin deficiency-induced obesity alters brain cytokine levels}

301 We measured TNF- $\alpha$ and IL-6 levels to evaluate whether a leptin deficiency alters inflammation status 302 in the brain. TNF- $\alpha$ levels were lower in ob/ob mice $(p<0.001)$ and IL-6 levels were higher in leptin303 deficient ob/ob mice than in wild-type mice $(p<0.001)$. The melatonin treatment also exerted different 304 effects on both strains by reducing TNF- $\alpha$ levels and increasing IL-6 levels in wild-type animals $(p<0.05$ for TNF- $\alpha$ and $p<0.001$ for IL-6) and increasing the levels of both cytokines in ob/ob mice ( $p<0.01$ for

306 TNF- $\alpha$ and $p<0.001$ for IL-6) (Fig. 2).

\section{The leptin deficiency increases ER stress}

309 Oxidative stress, inflammation and ER stress are concatenated processes that are usually activated in 310 cells in response to stress conditions [45]. Under many pathophysiological conditions, the ER stress 311 response termed the UPR attempts to alleviate protein misfolding and restore an efficient protein-folding 312 environment. The three signaling pathways of the UPR, inositol-requiring enzyme $1 \alpha$ (IRE1 $\alpha$ ), double313 stranded RNA-activated protein kinase (PKR)-like endoplasmic reticulum kinase (PERK), and 
314 activating transcription factor- $6 \alpha$ (ATF- $6 \alpha)$, were assessed to evaluate whether the UPR is activated in

315 the leptin-deficient mice [46,47]. Thus, the levels of IRE1 $\alpha$, p-eIF2 $\alpha$ (phosphorylated-eukaryotic 316 initiation factor $2 \alpha$ ) and ATF-6 $\alpha$ were measured. The levels of the IRE1 $\alpha$ protein were similar in both 317 strains of mice. Although the levels of p-eIF2 $\alpha$ were reduced in ob/ob mice $(p<0.001)$, the levels of 318 ATF-6 $\alpha$ pathway were increased $(p<0.01)$ in these obese individuals. Wild-type mice treated with 319 melatonin only exhibited an increase in the IRE1 $\alpha$ protein content $(p<0.01)$, which promotes cell

320 survival by optimizing the functions of the ER and the cell. In contrast, melatonin reduced the expression 321 of IRE1 $\alpha$ and ATF- $6 \alpha$ in ob/ob mice $(p<0.001$ for IRE1 $\alpha$ and $p<0.01$ for ATF- $6 \alpha$ ) by decreasing cellular 322 stress (Fig. 3a). The last cytoprotective branch of the UPR induces the expression of ER chaperones. 323 Heat shock cognate $71 \mathrm{kDa}$ (hsc70) protein belongs to the hsp70 family, whose main function is to 324 prevent protein misfolding and aggregation [48]. The ob/ob mice exhibited decreased expression of 325 hsc70 protein compared with wild-type animals $(p<0.001)$, whereas the melatonin treatment decreased 326 its expression in both strains of mice $(p<0.001$ for WC compared with $\mathrm{WM}$ and $p<0.001$ for ObC 327 compared with ObM) (Fig. 3b).

328 Based on our results, the accumulation of unfolded/misfolded proteins in ob/ob mice triggers the UPR, 329 which is characterized by the activation of ATF- $6 \alpha$. This increase in the ATF-6 $\alpha$ levels seems to be 330 required to facilitate tolerance to chronic stress [49]. The observed decrease in the IRE1 $\alpha$, ATF-6 $\alpha$ and 331 hsc70 levels induced by melatonin administration suggests an improvement in protein synthesis and 332 folding.

\section{Leptin-deficient mice exhibit reduced proteasome activity}

335 As brains from ob/ob mice exhibited an accumulation of unfolded/misfolded and oxidatively damaged 336 proteins, the cells may exhibit both a failure of the protein synthesis machinery or alterations in the 337 degradation systems. These proteins should be eliminated by different protein quality control 338 mechanisms, such as the ubiquitin-proteasome system. Leptin-deficient ob/ob animals showed a lower level of $20 \mathrm{~S}$ proteasome activity than wild-type mice $(p<0.001)$ (Fig. $4 \mathrm{a})$ and a subsequent accumulation

340 of ubiquitinated proteins $(p<0.001)$ (Fig. $4 \mathrm{~b})$. Proteasome activity was also reduced by the melatonin 341 treatment in both strains $(p<0.001)$ (Fig. 4a), but did not alter the amounts of ubiquitinated proteins, 
342 compared with the respective untreated group, which may be related to an improvement in protein 343 synthesis induced by this indolamine (Fig. 4b).

\section{Leptin-deficient ob/ob mice activate autophagy}

346 The accumulation of altered proteins together with the impairment of the proteasome-ubiquitin system 347 probably requires the activation of other protein quality control mechanisms to maintain protein 348 homeostasis in the brains from obese mice. Thus, we studied the autophagic pathways by measuring the 349 levels of lysosome-associated membrane protein type 2A (LAMP2A), a marker for CMA, and Beclin350 1, microtubule-associated protein 1 light chain 3 (LC3) and the p62 protein, markers of macroautophagy. 351 Leptin-deficient mice showed increased LAMP2A expression compared with wild-type animals $352(p<0.01)$ and the melatonin treatment reduced its expression $(p<0.01)$ to the levels detected in wild-type 353 animal (Fig. 5). Although ob/ob mice present impaired proteasome activity, CMA is triggered in an 354 attempt to remove the damaged and unfolded/misfolded proteins.

355 Beclin-1, which plays an essential role in initiating autophagy [50], was expressed at higher levels in 356 immunoblots of the brains from ob/ob mice than in the brains from wild-type animals $(p<0.001)$ (Fig. 357 5). The most frequently used autophagy marker is LC3, whose lipidated form, known as LC3-II, is 358 attached to the autophagosome membrane. Consistent with Beclin-1 results, the LC3-I and LC3-II 359 proteins were expressed at higher levels in ob/ob mice than in wild-type animals ( $p<0.05$ for LC 3 -I and $360 p<0.01$ for LC3-II), indicating that autophagosomes were formed in this leptin-deficient strain (Fig. 5). 361 In addition, the melatonin treatment decreased the levels of all these autophagic biomarkers $(p<0.001$ 362 for Beclin-1, $p<0.01$ for LC3-I and $p<0.001$ for LC3-II), suggesting that melatonin prevents the causes 363 that trigger the Beclin-1-dependent autophagy induced by the leptin deficiency in ob/ob mice (Fig. 5).

364 The p62 protein interacts with LC3 to remove protein aggregates and is considered a marker of 365 autophagic flux. The expression of the p62 protein was significantly increased in the ObC group $366(p<0.05)$, indicating that autophagic degradation was inefficient. This blockade seems to be resolved in 367 the ObM group, as p62 expression was reduced to control levels $(p<0.001)$. However, the levels of the 368 p62 protein were significantly increased in the WM group $(p<0.01)$, which may be related to antioxidant 369 defense support [51,52] and were further increased by melatonin (Fig. 5). 
371 cellular mechanisms for maintaining protein homeostasis.

\section{The leptin deficiency induces aggresome formation}

374 Cytoskeletal alterations are present in numerous diseases. Disruption of the cytoskeleton allows misfolded proteins to associate with cytoskeletal components and triggers the formation of inclusion bodies that are generically termed aggresomes [53]. Actin, microtubules, ubiquitinated proteins and vimentin, the intermediate filament that surrounds these elements, are main elements of these aggregates $378 \quad[54]$.

Immunoblots for $\beta$-actin and vimentin showed similar patterns, but $\alpha$-tubulin expression differed from the levels of these proteins. Brain extracts from leptin-deficient obese mice showed increased expression of $\beta$-actin, $\alpha$-tubulin and vimentin compared with wild-type animals $(p<0.001)$. However, the melatonin treatment increased the $\beta$-actin $(p<0.001)$ and vimentin $(p<0.05)$ levels and significantly decreased $\alpha$ tubulin expression in ob/ob mice $(p<0.001)$ (Fig. 6). Disruption of microtubules blocks aggresome

384 formation [55]; consequently, the significant decrease in the $\alpha$-tubulin levels seems to support reduced 385 aggresome formation in this experimental group.

386 The results observed in the ObC mice indicated effects on neuronal physiology and vesicle trafficking 387 and could lead to the expression of neurodegenerative markers.

\section{The leptin deficiency increases the accumulation of neurodegeneration markers}

390 Based on the our results suggesting that some protein quality control mechanisms were impaired and cytoskeletal rearrangements occurred in ob/ob mice and findings that abnormal aggregates of

392 cytoskeletal proteins are neuropathological signatures of many neurodegenerative diseases [56], we

393 studied the expression of the main neurodegeneration markers in our experimental model of morbid 394 obesity.

395 The $\beta$-amyloid and $\alpha$-synuclein proteins are markers of Alzheimer's disease (AD) and Parkinson's 396 disease (PD), respectively, and their deposition is also detected during age-related neurodegeneration. 
Although ob/ob and wild-type mice presented equal amounts of the $\beta$-amyloid protein, with an unexpected, significant increase in wild-type animals treated with melatonin, ob/ob animals exhibited a significant increase in $\alpha$-synuclein expression $(p<0.05)$ (Fig. 7a). Abnormal hyperphosphorylation of the microtubule-associated protein Tau is frequently observed in neurodegenerative diseases such as $\mathrm{AD}$ and even in normal age-related neurodegeneration. We analyzed four Tau phosphorylation sites: Tau p-S ${ }^{199}$, Tau $\mathrm{p}-\mathrm{T}^{205}$, Tau $\mathrm{p}-\mathrm{S}^{396}$ and Tau $\mathrm{p}-\mathrm{S}^{404}$. The levels of

403 phosphorylation at these sites were similar but were significantly higher in brains from leptin-deficient ob/ob mice ( $p<0.05$ for Tau $\mathrm{p}-\mathrm{S}^{199}, p<0.001$ for Tau $\mathrm{p}-\mathrm{T}^{205}, p<0.01$ for Tau $\mathrm{p}-\mathrm{S}^{396}$ and $p<0.001$ for Tau p-S $\mathrm{S}^{404}$ ) (Fig. 7b). Although the melatonin treatment did not alter the $\beta$-amyloid content in ob/ob mice, it induced a significant decrease in the $\alpha$-synuclein $(p<0.05)$ (Fig. 7a) and phosphorylated Tau protein expression to the levels detected in wild-type mice $\left(p<0.001\right.$ for Tau $\mathrm{p}-\mathrm{S}^{199}, p<0.001$ for Tau $\mathrm{p}-\mathrm{T}^{205}$, $p<0.001$ for Tau $\mathrm{p}-\mathrm{S}^{396}$ and $p<0.001$ for Tau $\mathrm{p}-\mathrm{S}^{404}$ ) (Fig. $7 \mathrm{~b}$ ).

409 In summary, based on the results presented in this section, leptin deficiency-induced obesity increases 410 the accumulation of neurodegeneration markers, mainly markers of tauopathies, and melatonin is able 411 to restore the normal levels of these markers.

\section{Leptin-deficient mice exhibit distinct stress-induced behaviors}

414 All previous alterations and failures at the cellular level observed in the brains of ob/ob mice could have behavioral implications and may be correlated with behavioral changes in response to an acute stressful 416 and aversive situation. Therefore, we evaluated the possible stress-induced behaviors using the PST.

417 Our results showed significant differences between ob/ob and wild-type mice, as the leptin-deficient 418 mice exhibited lower immobility latency times $(p<0.001)$ (Fig. 8a). This increase in mobility revealed 419 an escape behavior that suggested a lower state of hopelessness in ob/ob animals than in wild-type mice 420 (Fig. 8b). The melatonin treatment did not alter the stress-induced behaviors of wild-type animals, but 421 it reversed this behavior in leptin-deficient mice by reducing mobility and increasing immobility to the 422 levels observed in wild-type animals $(p<0.001)$ (Fig. 8).

423 Thus, the cellular alterations detected in the brains of leptin-deficient mice induce changes in behaviors 424 by increasing the animals' perception of stress and probably their susceptibility to anxiety. 


\section{Discussion}

427 Obesity, a medical condition that has reached epidemic levels worldwide, is a key factor in several 428 widely studied diseases, such as bone and muscle diseases, heart diseases and type 2 diabetes [57]. 429 Although obesity has been shown to affect the organism from the biochemical level to the tissue level, 430 its effects on the brain, particularly the impact of obesity-induced damage on the brain, have been poorly 431 studied. Therefore, we studied the effects of obesity on cellular mechanisms and showed that obesity 432 induced widespread brain effects that may underlie neurodegenerative disorders ultimately 433 compromising the behavior. Association between obesity and dementia risk are being studied [4].

434 Morbid obesity, such as is induced in ob/ob mice by leptin absence [58], induced a significant decrease 435 in brain weight in our animals, even though the net body weight of the ob/ob mice was significantly increased compared to the wild-type mice. A similar decrease in brain volume is usually observed during

437 aging and is related to changes in cognition [59]. This concomitant decrease may be the first evidence 438 of cerebral damage.

439 The decrease in brain volume is not the only similarity between the effects of obesity and aging on the 440 brain. Oxidative stress occurs in aged brain [60,61], and increased food intake causes the excessive 441 oxidation of glucose and exacerbates ROS production [62]. In our obese animals, these changes were 442 manifested as a significant increase in protein damage that was not reduced by GSSG-Px/GR. The 443 tandem dysregulation of SOD and CAT activities magnifies this damage. As shown in aged brains, 444 melatonin was able to counteract this damage and significantly reduces brain damage by restoring and 445 increasing the antioxidant activities of SOD and CAT $[63,64]$.

446 The oxidative stress observed in the brains of our obese animals dysregulates inflammation by inducing 447 a clear increase in the IL-6 levels and a decrease in the TNF- $\alpha$ levels. IL- 6 and leptin are adipokines, 448 and both proteins, together with their receptors, share structural and functional similarities in regulating 449 the immune response [65]. Thus, IL-6 expression is increased in response to oxidative stress, generating 450 a protective anti-inflammatory effect that, in turn, inhibits TNF- $\alpha$ production [66]. The melatonin 451 treatment enhanced this protective effect of IL-6 on both obese and wild-type animals. Likewise, the 
slight increase in TNF- $\alpha$ production observed in melatonin-treated obese mice may result from

453 melatonin-induced improvements in the immune system, consistent with several previous reports [67-

454 69]. These data agree with the decrease in the levels of this cytokine in obese animals, where the close 455 relationship between leptin and TNF- $\alpha$ must be assessed [65], since both cytokines exert synergistic 456 effects and in the absence of one cytokine, the levels of the other may be reduced. Nevertheless, TNF- $\alpha$ 457 reduces food intake and participates in regulating energy homeostasis [70]; in the absence of leptin and 458 the presence of reduced TNF- $\alpha$ levels, energy homeostasis is expected to be deregulated, suggesting that 459 the protein synthesis and degradation pathways are impaired.

460 According to previous studies, including studies from our own group, obesity induces ER stress in 461 different organs [13,66-68]. However, the UPR in the brain has specific and dangerous consequences, 462 since oxidative stress and protein misfolding play critical roles in the pathogenesis of neurodegenerative 463 diseases [71-73] and dementia [74]. The ER has an essential role in neurotransmitter synthesis; therefore,

464 ER stress implies that protein folding efficiency is decreasing, which may contribute to abnormalities in 465 the neuronal circuitry that may represent a preliminary stage of neurological disorders [75]. Oxidative 466 stress and ER stress are observed in the brains of obese animals, as shown by the changes in the main 467 signaling cascades. However, the signals required to trigger these pathways are missing. The primary 468 target of IRE-1 $\alpha / \mathrm{XBP} 1$ activation is the $26 \mathrm{~S}$ proteasome [73] to reduce the levels of misfolded proteins, 469 but obese animals showed decreased 20S proteasome activity. Likewise, ATF-6 $\alpha$ is cleaved to yield a 470 fragment that migrates to the nucleus to activate the transcription of chaperone genes [76], but the levels 471 of hsc70, one of the most important chaperones that integrates in the hsp70 system and is responsible 472 for preventing aggregation and remodeling folding pathways [48], are significantly reduced in obese 473 animals. Although the UPR is correctly triggered by the misfolded proteins, subsequent transcriptional 474 activation is not produced. These obesity-induced impairments are consistent with data observed in 475 aging models [77], as the ability to activate the UPR decreases with age. The significant increase in the 476 levels of ubiquitinated proteins observed in the obese animals indicates that ER stress is not being 477 resolved. Proteasome dysfunction has been widely documented in obese subjects [78,79]; however, this 478 study is the first to show the deterioration of the UPR signaling cascade in obese animals. 
The treatment with melatonin induced a total recovery. Accumulating data support the hypothesis that 480 protein folding and the generation of free radicals in the ER as byproducts of protein oxidation are 481 closely associated events [73]. Under these circumstances, the action of potent antioxidants, such as melatonin, is very beneficial. A minimal UPR was observed in obese animals treated with melatonin because the production of misfolded proteins was drastically reduced; these data were corroborated by 484 the substantial reduction in the levels of ubiquitinated proteins in this experimental group.

485 Degradation of misfolded proteins only occurs through the proteasome or autophagy. Both CMA and 486 macroautophagy were up-regulated in our obese animals. This situation reduced the levels of misfolded 487 proteins, although misfolded proteins were still present, as shown in the blots of the ubiquitinated proteins. However, this status quo cannot be maintained. Thus, Ignacio-Souza and coworkers [79] showed that prolonged obesity, but not short-term, trying to maintain rate of protein recycling, induced eventually ubiquitin/proteasome and autophagy fails. Similar data were observed in our unpublished data from human muscles obtained from overweight aged people [80]. Thus, sustained autophagy fails to remove all damaged structures and directs the cell to programmed cell death. The significant increase in the p62 levels observed in the obese animals showed that autophagy was not as efficient as needed.

494 The melatonin treatment, which reduces ER stress and oxidative stress in the cell, reduces the need for autophagy, and thus autophagy was significantly reduced in this experimental group. However, the increased p62 levels observed in control animals treated with melatonin may be noteworthy. P62 is a multifunctional molecule and the meaning of this result requires additional information. Therefore,

498 considering the data from the ER stress, oxidative stress, UPR cascade and autophagy experiments, the 499 most likely role of p62 is to counteract oxidative stress and enhance cell protection by interacting with 500 nuclear factor-erythroid 2-related factor 2 (Nrf2), as suggested by some authors [52,81]. Thus, our 501 results about p62 in the treated wild-type animals are probably related with the antioxidant properties of melatonin.

503 Aggresomes are inclusion bodies composed of misfolded proteins that are aggregated in a single 504 structure mainly in the central region of the cell [54]. However, several other molecules can be also 505 incorporated in aggresomes by synergistic actions. Thus, several cytoskeleton components are present 506 in aggresomes as a result of cytoskeletal disruptions, including intermediate filaments [53], filamentous 
actin [82] and, mainly in the central nervous system, microtubules, which have dangerous consequences

508 regarding the transport of neurotransmitters [83]. These aggresomes are also enriched in ubiquitin, a marker of misfolded proteins, and p62, as this molecule acts a bridge between ubiquitin-protein aggregates and the autophagosomal system [83]. Inefficient autophagy leads to the accumulation of autophagosomes enriched in p62 and misfolded/unfolded proteins that assist in the construction of aggresomes. In obese animals, the levels of p62 and misfolded proteins were increased. Cytoskeletal rearrangements are also evident, based on the significant increase in the levels of actin, tubulin and

514 vimentin, supporting the presence of aggresomes. The intermediate filament vimentin is redistributed 515 during aggresome formation to form a cage surrounding a pericentriolar core composed of ubiquitinated proteins [55]; therefore, the increase in the vimentin levels should be related to aggresome formation. Aggresomes gain special importance in obese animals when the brain is the target, since they play a main role in brain deterioration and directly interact with the hyperphosphorylated Tau protein observed in these animals, which also forms part of the aggresome [84].

520 Tau is a highly soluble protein with multiple phosphorylation sites [85]. Its microtubule binding activity 521 is mainly regulated by phosphorylation, and microtubule assembly is promoted by this posttranslational modification, which stabilizes the microtubule network. However, Tau hyperphosphorylation reduces its capability to bind microtubules [86] and is present in a large number of neurodegenerative disorders known as tauopathies [87]. Likewise, filamentous actin interacts with Tau proteins in inclusion bodies in $\mathrm{AD}[54,82]$. Phosphorylation at four Tau sites was significantly increased in obese animals and are included in the 30 phosphorylation sites observed in the brain of AD patients [87], indicating that obesity

527 may be implicated in tauopathies development. Together with these neurodegenerative markers, the $\alpha$ synuclein levels were also increased in ob/ob animals. Its accumulation seems to be induced by the oxidative environment, misfolded proteins, accelerated aggregation and impairments in degradation systems, which contribute to the pathogenesis of synucleinopathies $[83,88]$.

531 The melatonin treatment produced a drastic effect on $\alpha$-synuclein accumulation, hyperphosphorylation 532 of Tau and aggresome formation. Melatonin efficiently protects neuronal cells and attenuates 533 Alzheimer-like Tau hyperphosphorylation via its antioxidant properties [87]. In our study, melatonin 534 significantly reduced phosphorylation at the four Tau sites studied to the basal level, inhibiting the 
development of cognitive deficits associated with some tauopathies [89]. Regarding aggresome

536 formation, the effect of melatonin seems to be mediated by a cascade consisting of reduced oxidative stress and minimized ER stress to resolve protein misfolding. Thus, autophagy overactivity is not required to avoid aggresome formation. Moreover, various authors have revealed the importance of microtubules in the formation and clearance of aggresomes [54,84]; therefore, a significant reduction in $\alpha$-tubulin expression in the ObM group is expected to decrease the number of these inclusion bodies.

541 This effect of melatonin as an inducer of a mechanism preventing aggresome formation was previously 542 unknown.

543 Tauopathies [90] and synucleinopathies [91] have been described to induce cognitive deficits.

544 Consequently, all cellular damage observed in the brains of obese animals, together with Tau hyperphosphorylation and $\alpha$-synuclein accumulation, could promote abnormal behaviors. To test this hypothesis in our experimental model, we used the PST that measure anxiety- and/or depression-related

547 behaviors since these behaviors are common and prodromal symptoms of neurodegenerative diseases 548 [92-95]. Although the PST allows us to study depression-related factors, the PST is not a sufficient 549 screen for depression.

550 Although several studies have correlated low leptin levels in the plasma or cerebrospinal fluid with a risk of major depression (REFs), leptin deficiency-induced obesity increases mobility latency times, suggesting an increase in the animals' perception of stress and anxiety [96,97]. On the other hand, the

553 accumulation of abnormally hyperphosphorylated Tau proteins increases anxiety-related behaviors $554 \quad[98,99]$.

555 As discussed above, melatonin significantly reduces the negative effects of obesity on the brain, which 556 may be sufficient to explain the recovery in stress-induced behaviors until control levels observed in 557 melatonin-treated obese mice, which presented similar mobility latency times than wild-type animals. 558 Moreover, anxiolytic and antidepressant-like effects were attributed to melatonin [95,100]. These 559 multifactorial actions of melatonin are certainly the reason for the evident improvements in the behaviors 560 of the treated obese animals.

561 In summary, morbid obesity, which was induced by a leptin deficiency in the ob/ob animals, provokes

562 significant alterations in the brain at cellular level that altered their behaviors. Oxidative stress is 
accompanied by ER stress in the brains of these animals. Thus, UPR and protein degradation systems

564 (proteasome, CMA, autophagy, etc.) begin to be overwhelmed, aggresomes are formed, and neurodegenerative markers are expressed, all of which are also present in non-pathological aging. Aggresomes always have harmful effects on cell transport, but they are particularly deleterious to postmitotic neurons, which require neurotransmitter transport and have no capacity to dilute protein aggregates by cell division, leading to cell death. Finally, these alterations increase the animals' perception of stress and anxiety.

Melatonin improves the antioxidant defense system by reducing the levels of damaged and unfolded/misfolded proteins, thus attenuating the failure of the protein repair and degradation systems and decreasing the levels of protein aggregates and brain damage caused by obesity. Additionally, the melatonin treatment decreases the stress-induced behaviors and anxiety. Therefore, our results suggest that melatonin is a potential therapeutic agent that protects against brain damage in obesity specifically

575 tested.

\section{Acknowledgments}

We are members of the cROS group and the INPROTEOLYS and INEUROPA networks. This work was supported by FISS-13-RD12/0043/0030, FISS-13-RD12/0043/0017 and FISS-14-PI13/02741 (Instituto de Salud Carlos III, Spanish Ministry of Economy and Competitiveness), FC-15-GRUPIN14-

581071 (FICYT, PCTI, Principado de Asturias) and FEDER funds. A. Rubio-González and Z. Pérez582 Martínez are pre-doctoral hireds (FC-15-GRUPIN14-071) from FICYT, PCTI (Principado de Asturias). 583 Y. Potes is a FISS pre-doctoral fellow (FI14/00405) from the Instituto de Salud Carlos III (Spanish 584 Ministry of Economy and Competitiveness).

\section{Conflict of interest}

587 The authors declare that they have no conflict of interest.

\section{References}


1. WHO (2015) Obesity and Overweight. World Health Organization (WHO).

591 http://www.who.int/mediacentre/factsheets/fs311/es/. Accessed 6 March 2017

592 2. Haslam DW, James WP (2005) Obesity. Lancet 366:1197-1209. doi:10.1016/S0140-6736(05)67483$593 \quad 1$

594 3. Beydoun MA, Beydoun HA, Wang Y (2008) Obesity and central obesity as risk factors for incident 595 dementia and its subtypes: a systematic review and meta-analysis. Obesity reviews : an official journal 596 of the International Association for the Study of Obesity 9:204-218. doi:10.1111/j.1467$597 \quad 789 X .2008 .00473 . x$

598 4. Lee EB, Mattson MP (2014) The neuropathology of obesity: insights from human disease. Acta 599 neuropathologica 127:3-28. doi:10.1007/s00401-013-1190-x

600 5. Marwarha G, Dasari B, Prasanthi JR, Schommer J, Ghribi O (2010) Leptin reduces the accumulation 601 of Abeta and phosphorylated tau induced by 27-hydroxycholesterol in rabbit organotypic slices. Journal 602 of Alzheimer's disease : JAD 19:1007-1019. doi:10.3233/JAD-2010-1298

603 6. Raichle ME, Gusnard DA (2002) Appraising the brain's energy budget. Proceedings of the National 604 Academy of Sciences of the United States of America 99:10237-10239. doi:10.1073/pnas.172399499 605 7. Reiter RJ (1995) Oxidative processes and antioxidative defense mechanisms in the aging brain. 606 FASEB journal : official publication of the Federation of American Societies for Experimental Biology $607 \quad 9: 526-533$

608 8. Boland B, Kumar A, Lee S, Platt FM, Wegiel J, Yu WH, Nixon RA (2008) Autophagy induction and 609 autophagosome clearance in neurons: relationship to autophagic pathology in Alzheimer's disease. The 610 Journal of neuroscience : the official journal of the Society for Neuroscience 28:6926-6937. 611 doi:10.1523/JNEUROSCI.0800-08.2008

612 9. Hoyer-Hansen M, Jaattela M (2007) Connecting endoplasmic reticulum stress to autophagy by 613 unfolded protein response and calcium. Cell death and differentiation 14:1576-1582. 614 doi:10.1038/sj.cdd.4402200

615 10. Zhang N, Cao MM, Liu H, Xie GY, Li YB (2015) Autophagy regulates insulin resistance following 616 endoplasmic reticulum stress in diabetes. Journal of physiology and biochemistry 71:319-327. 617 doi:10.1007/s13105-015-0384-1 
618 11. Bence NF, Sampat RM, Kopito RR (2001) Impairment of the ubiquitin-proteasome system by 619 protein aggregation. Science 292:1552-1555. doi:10.1126/science.292.5521.1552

620 12. Coto-Montes A, Boga JA, Rosales-Corral S, Fuentes-Broto L, Tan DX, Reiter RJ (2012) Role of 621 melatonin in the regulation of autophagy and mitophagy: a review. Molecular and cellular 622 endocrinology 361:12-23. doi:10.1016/j.mce.2012.04.009

623 13. de Luxan-Delgado B, Potes Y, Rubio-Gonzalez A, Caballero B, Solano JJ, Fernandez-Fernandez M, 624 Bermudez M, Rodrigues Moreira Guimaraes M, Vega-Naredo I, Boga JA, Coto-Montes A (2016) 625 Melatonin reduces endoplasmic reticulum stress and autophagy in liver of leptin-deficient mice. Journal 626 of pineal research 61:108-123. doi:10.1111/jpi.12333

627 14. Bonda DJ, Stone JG, Torres SL, Siedlak SL, Perry G, Kryscio R, Jicha G, Casadesus G, Smith MA, Zhu X, Lee HG (2014) Dysregulation of leptin signaling in Alzheimer disease: evidence for neuronal leptin resistance. Journal of neurochemistry 128:162-172. doi:10.1111/jnc.12380

630 15. Turner RT, Philbrick KA, Wong CP, Olson DA, Branscum AJ, Iwaniec UT (2014) Morbid obesity 631 attenuates the skeletal abnormalities associated with leptin deficiency in mice. The Journal of 632 endocrinology 223:M1-15. doi:10.1530/JOE-14-0224

633 16. Reiter RJ, Tan DX, Korkmaz A, Ma S (2012) Obesity and metabolic syndrome: association with 634 chronodisruption, sleep deprivation, and melatonin suppression. Annals of medicine 44:564-577. doi:10.3109/07853890.2011.586365

636 17. Vega-Naredo I, Caballero B, Sierra V, Garcia-Macia M, de Gonzalo-Calvo D, Oliveira PJ, 637 Rodriguez-Colunga MJ, Coto-Montes A (2012) Melatonin modulates autophagy through a redox638 mediated action in female Syrian hamster Harderian gland controlling cell types and gland activity. 639 Journal of pineal research 52 (1):80-92. doi:10.1111/j.1600-079X.2011.00922.x

640 18. Mastronardi CA, Walczewska A, Yu WH, Karanth S, Parlow AF, McCann SM (2000) The possible 641 role of prolactin in the circadian rhythm of leptin secretion in male rats. Proc Soc Exp Biol Med 224:152$642 \quad 158$

643 19. Agil A, Rosado I, Ruiz R, Figueroa A, Zen N, Fernandez-Vazquez G (2012) Melatonin improves 644 glucose homeostasis in young Zucker diabetic fatty rats. Journal of pineal research 52:203-210. 645 doi:10.1111/j.1600-079X.2011.00928.x 
647 pinealectomy and exogenous melatonin on serum leptin levels in male rat. European journal of 648 pharmacology 428:145-148

649 21. Baydas G, Gursu F, Canpolat S, Konar V, Yasar A, Canatan H, Kelestimur H (2001) Effects of 650 pinealectomy on the circadian release pattern of leptin in male rat. Neuro endocrinology letters 22:449651452

652 22. Manchester LC, Coto-Montes A, Boga JA, Andersen LP, Zhou Z, Galano A, Vriend J, Tan DX, 653 Reiter RJ (2015) Melatonin: an ancient molecule that makes oxygen metabolically tolerable. Journal of 654 pineal research 59:403-419. doi:10.1111/jpi.12267

655 23. Reiter RJ, Mayo JC, Tan DX, Sainz RM, Alatorre-Jimenez M, Qin L (2016) Melatonin as an 656 antioxidant: under promises but over delivers. Journal of pineal research 61:253-278. 657 doi:10.1111/jpi.12360

658 24. Tan DX, Manchester LC, Fuentes-Broto L, Paredes SD, Reiter RJ (2011) Significance and 659 application of melatonin in the regulation of brown adipose tissue metabolism: relation to human 660 obesity. Obesity reviews : an official journal of the International Association for the Study of Obesity 661 12:167-188. doi:10.1111/j.1467-789X.2010.00756.x

662 25. Jimenez-Aranda A, Fernandez-Vazquez G, Campos D, Tassi M, Velasco-Perez L, Tan DX, Reiter 663 RJ, Agil A (2013) Melatonin induces browning of inguinal white adipose tissue in Zucker diabetic fatty 664 rats. Journal of pineal research 55:416-423. doi:10.1111/jpi.12089

665 26. Lima FB, Machado UF, Bartol I, Seraphim PM, Sumida DH, Moraes SM, Hell NS, Okamoto MM, 666 Saad MJ, Carvalho CR, Cipolla-Neto J (1998) Pinealectomy causes glucose intolerance and decreases 667 adipose cell responsiveness to insulin in rats. The American journal of physiology 275:E934-941

668 27. Kozirog M, Poliwczak AR, Duchnowicz P, Koter-Michalak M, Sikora J, Broncel M (2011) 669 Melatonin treatment improves blood pressure, lipid profile, and parameters of oxidative stress in patients 670 with metabolic syndrome. Journal of pineal research 50:261-266. doi:10.1111/j.1600$671 \quad$ 079X.2010.00835.x

672 28. Wu H, Shao A, Zhao M, Chen S, Yu J, Zhou J, Liang F, Shi L, Dixon BJ, Wang Z, Ling C, Hong 673 Y, Zhang J (2016) Melatonin attenuates neuronal apoptosis through up-regulation of $\mathrm{K}(+)-\mathrm{Cl}(-)$ 
674 cotransporter KCC2 expression following traumatic brain injury in rats. Journal of pineal research 675 61:241-250. doi:10.1111/jpi.12344

676 29. Castracane VD, Henson MC (2007) The obese (ob/ob) mouse and the discovery of leptin. In: 677 Castracane VD, Henson MC (eds) Leptin. Endocrine Updates, vol 25. Springer US, New York City, 678 NY, USA, pp 1-9. doi:10.1007/978-0-387-31416-7_1

679 30. Bradford MM (1976) A rapid and sensitive method for the quantitation of microgram quantities of 680 protein utilizing the principle of protein-dye binding. Analytical biochemistry 72:248-254

681 31. Levine RL, Garland D, Oliver CN, Amici A, Climent I, Lenz AG, Ahn BW, Shaltiel S, Stadtman 682 ER (1990) Determination of carbonyl content in oxidatively modified proteins. Methods in enzymology $683 \quad 186: 464-478$

684 32. Coto-Montes A, Hardeland R (1999) Antioxidative effects of melatonin in Drosophila melanogaster: 685 antagonization of damage induced by the inhibition of catalase. Journal of pineal research 27:154-158 686 33. Arnao MB, Cano A, Acosta M (2001) The hydrophilic and lipophilic contribution to total antioxidant 687 activity. Food Chemistry 73:239-244

688 34. de Gonzalo-Calvo D, Neitzert K, Fernandez M, Vega-Naredo I, Caballero B, Garcia-Macia M, 689 Suarez FM, Rodriguez-Colunga MJ, Solano JJ, Coto-Montes A (2010) Differential inflammatory 690 responses in aging and disease: TNF-alpha and IL-6 as possible biomarkers. Free radical biology \& 691 medicine 49:733-737. doi:10.1016/j.freeradbiomed.2010.05.019

692 35. Martin JP, Jr., Dailey M, Sugarman E (1987) Negative and positive assays of superoxide dismutase 693 based on hematoxylin autoxidation. Archives of biochemistry and biophysics 255:329-336

694 36. Lubinsky S, Bewley GC (1979) Genetics of Catalase in DROSOPHILA MELANOGASTER: Rates 695 of Synthesis and Degradation of the Enzyme in Flies Aneuploid and Euploid for the Structural Gene. 696 Genetics 91:723-742

697 37. Kum-Tatt L, Tan IK, Seet AM (1975) A new colorimetric method for the determination of 698 NADH/NADPH dependent glutathione reductase in erythrocytes and in plasma. Clinica chimica acta; 699 international journal of clinical chemistry 58:101-108

700 38. Goldberg DM, Spooner RJ (1983) Glutathione reductase. In: Bergmeyer HU (ed) Methods of 701 enzymatic analysis. 3rd ed. edn. Verlag Chemie, Deerfield Beach, FL, pp 258-265 
39. Nugent BM, Wright CL, Shetty AC, Hodes GE, Lenz KM, Mahurkar A, Russo SJ, Devine SE,

703

704

705

706

707

708

709

710

711

712

713

714

715

716

717

718

719

720

721

722

723

724

725

726

727

McCarthy MM (2015) Brain feminization requires active repression of masculinization via DNA methylation. Nature neuroscience 18 (5):690-697. doi:10.1038/nn.3988

40. Oliván M, Fernández-Suárez V, Díaz-Martínez F, Sierra V, Coto-Montes A, de Luxán-Delgado B, Peña R, Bassols A, Fàbrega E, Dalmau A, Velarde A (2016) Identification of biomarkers of stress in meat of pigs managed under different mixing treatments. British Biotechnology Journal 11:1-13. doi:10.9734/BBJ/2016/22402

41. Havlis J, Thomas H, Sebela M, Shevchenko A (2003) Fast-response proteomics by accelerated ingel digestion of proteins. Analytical chemistry 75:1300-1306

42. Jami MS, Barreiro C, Garcia-Estrada C, Martin JF (2010) Proteome analysis of the penicillin producer Penicillium chrysogenum: characterization of protein changes during the industrial strain improvement. Molecular \& cellular proteomics : MCP 9:1182-1198. doi:10.1074/mcp.M900327-

\section{MCP200}

43. Porsolt RD, Bertin A, Jalfre M (1977) Behavioral despair in mice: a primary screening test for antidepressants. Archives internationales de pharmacodynamie et de therapie 229:327-336

44. Gersner R, Dar DE, Shabat-Simon M, Zangen A (2005) Behavioral analysis during the forced swimming test using a joystick device. Journal of neuroscience methods 143:117-121. doi:10.1016/j.jneumeth.2004.09.017

45. Dandekar A, Mendez R, Zhang K (2015) Cross talk between ER stress, oxidative stress, and inflammation in health and disease. Methods in molecular biology 1292:205-214. doi:10.1007/978-14939-2522-3_15

46. Yoo YM (2013) Melatonin-mediated insulin synthesis during endoplasmic reticulum stress involves HuD expression in rat insulinoma INS-1E cells. Journal of pineal research 55:207-220. doi:10.1111/jpi.12064

47. Yoshida H, Matsui T, Hosokawa N, Kaufman RJ, Nagata K, Mori K (2003) A time-dependent phase shift in the mammalian unfolded protein response. Developmental cell 4:265-271 
48. Mashaghi A, Bezrukavnikov S, Minde DP, Wentink AS, Kityk R, Zachmann-Brand B, Mayer MP,

Kramer G, Bukau B, Tans SJ (2016) Alternative modes of client binding enable functional plasticity of Hsp70. Nature 539:448-451. doi:10.1038/nature20137

49. Wu J, Rutkowski DT, Dubois M, Swathirajan J, Saunders T, Wang J, Song B, Yau GD, Kaufman

RJ (2007) ATF6alpha optimizes long-term endoplasmic reticulum function to protect cells from chronic

733

734 stress. Developmental cell 13:351-364. doi:10.1016/j.devcel.2007.07.005

50. Vega-Naredo I, Caballero B, Sierra V, Huidobro-Fernandez C, de Gonzalo-Calvo D, Garcia-Macia M, Tolivia D, Rodriguez-Colunga MJ, Coto-Montes A (2009) Sexual dimorphism of autophagy in Syrian hamster Harderian gland culminates in a holocrine secretion in female glands. Autophagy 5:1004-1017

51. Reinisalo M, Karlund A, Koskela A, Kaarniranta K, Karjalainen RO (2015) Polyphenol Stilbenes: Molecular Mechanisms of Defence against Oxidative Stress and Aging-Related Diseases. Oxidative medicine and cellular longevity 2015:340520. doi:10.1155/2015/340520

52. Rusten TE, Stenmark H (2010) p62, an autophagy hero or culprit? Nature cell biology 12:207-209. doi:10.1038/ncb0310-207

53. Kopito RR (2000) Aggresomes, inclusion bodies and protein aggregation. Trends in cell biology $10: 524-530$

54. Lazaro-Dieguez F, Aguado C, Mato E, Sanchez-Ruiz Y, Esteban I, Alberch J, Knecht E, Egea G (2008) Dynamics of an F-actin aggresome generated by the actin-stabilizing toxin jasplakinolide. Journal of cell science 121:1415-1425. doi:10.1242/jcs.017665

55. Johnston JA, Ward CL, Kopito RR (1998) Aggresomes: a cellular response to misfolded proteins. The Journal of cell biology 143:1883-1898

56. Cairns NJ, Lee VM, Trojanowski JQ (2004) The cytoskeleton in neurodegenerative diseases. The Journal of pathology 204:438-449. doi:10.1002/path.1650

57. Cao JJ (2011) Effects of obesity on bone metabolism. Journal of orthopaedic surgery and research 6:30. doi:10.1186/1749-799X-6-30

58. Dubern B, Clement K (2012) Leptin and leptin receptor-related monogenic obesity. Biochimie 94:2111-2115. doi:10.1016/j.biochi.2012.05.010 
59. Hedman AM, van Haren NE, Schnack HG, Kahn RS, Hulshoff Pol HE (2012) Human brain changes across the life span: a review of 56 longitudinal magnetic resonance imaging studies. Human brain mapping 33:1987-2002. doi:10.1002/hbm.21334

60. Caballero B, Coto-Montes A (2012) An insight into the role of autophagy in cell responses in the aging and neurodegenerative brain. Histology and histopathology 27:263-275. doi:10.14670/HH-27.263 61. Alvarez-Garcia O, Vega-Naredo I, Sierra V, Caballero B, Tomas-Zapico C, Camins A, Garcia JJ, Pallas M, Coto-Montes A (2006) Elevated oxidative stress in the brain of senescence-accelerated mice at 5 months of age. Biogerontology 7:43-52. doi:10.1007/s10522-005-6041-2

62. Manna P, Jain SK (2015) Obesity, Oxidative Stress, Adipose Tissue Dysfunction, and the Associated Health Risks: Causes and Therapeutic Strategies. Metabolic syndrome and related disorders 13:423444. doi:10.1089/met.2015.0095

63. Caballero B, Vega-Naredo I, Sierra V, Huidobro-Fernandez C, Soria-Valles C, De Gonzalo-Calvo Favorable effects of a prolonged treatment with melatonin on the level of oxidative damage and neurodegeneration in senescence-accelerated mice. Journal of pineal research 45:302-311. doi:10.1111/j.1600-079X.2008.00591.x D, Tolivia D, Pallas M, Camins A, Rodriguez-Colunga MJ, Coto-Montes A (2009) Melatonin alters cell death processes in response to age-related oxidative stress in the brain of senescence-accelerated mice. Journal of pineal research 46:106-114. doi:10.1111/j.1600-079X.2008.00637.x

65. Fantuzzi G, Faggioni R (2000) Leptin in the regulation of immunity, inflammation, and 777 hematopoiesis. Journal of leukocyte biology 68:437-446 66. Erta M, Quintana A, Hidalgo J (2012) Interleukin-6, a major cytokine in the central nervous system. International journal of biological sciences 8:1254-1266. doi:10.7150/ijbs.4679

780 67. Pierpaoli W (1998) Neuroimmunomodulation of aging. A program in the pineal gland. Annals of 781 the New York Academy of Sciences 840:491-497

782 68. Szczepanik M (2007) Melatonin and its influence on immune system. Journal of physiology and 783 pharmacology : an official journal of the Polish Physiological Society 58 Suppl 6:115-124 
Melatonin: buffering the immune system. International journal of molecular sciences 14:8638-8683. doi:10.3390/ijms 14048638

70. Rizk NM, Stammsen D, Preibisch G, Eckel JR (2001) Leptin and Tumor Necrosis Factor-alpha Induce the Tyrosine Phosphorylation of Signal Transducer and Activator of Transcription Proteins in the Hypothalamus doi:10.1210/endo.142.7.8225

71. Lee H, Noh JY, Oh Y, Kim Y, Chang JW, Chung CW, Lee ST, Kim M, Ryu H, Jung YK (2012) IRE1 plays an essential role in ER stress-mediated aggregation of mutant huntingtin via the inhibition of autophagy flux. Human molecular genetics 21:101-114. doi:10.1093/hmg/ddr445 and neurodegeneration: At the intersection between Alzheimer's disease and Prion-related disorders. Virus research 207:69-75. doi:10.1016/j.virusres.2014.12.018 73. Malhotra JD, Kaufman RJ (2007) Endoplasmic reticulum stress and oxidative stress: a vicious cycle or a double-edged sword? Antioxidants \& redox signaling 9:2277-2293. doi:10.1089/ars.2007.1782 74. Mizuno D, Kawahara M (2013) The molecular mechanisms of zinc neurotoxicity and the

800 pathogenesis of vascular type senile dementia. International journal of molecular sciences 14:2206722081. doi:10.3390/ijms141122067

802 75. Nosyreva E, Kavalali ET

(2010) Activity-dependent augmentation of spontaneous 803 neurotransmission during endoplasmic reticulum stress. The Journal of neuroscience : the official 804 journal of the Society for Neuroscience 30:7358-7368. doi:10.1523/JNEUROSCI.5358-09.2010 76. Volmer R, Ron D (2015) Lipid-dependent regulation of the unfolded protein response. Current opinion in cell biology 33:67-73. doi:10.1016/j.ceb.2014.12.002

807 77. Taylor RC (2016) Aging and the UPR(ER). Brain research 1648:588-593. 808 doi:10.1016/j.brainres.2016.04.017

809 78. Bollinger LM, Powell JJ, Houmard JA, Witczak CA, Brault JJ (2015) Skeletal muscle myotubes in 810 severe obesity exhibit altered ubiquitin-proteasome and autophagic/lysosomal proteolytic flux. Obesity $811 \quad 23: 1185-1193$. doi:10.1002/oby.21081 
813 de Moura RF, Nascimento LF, Arruda AP, Anhe GF, Milanski M, Velloso LA (2014) Defective

814 regulation of the ubiquitin/proteasome system in the hypothalamus of obese male mice. Endocrinology

815 155:2831-2844. doi:10.1210/en.2014-1090

816 80. Potes Y, de Luxan-Delgado B, Rodriguez-Gonzalez S, Guimaraes MRM, Solano JJ, Fernandez-

817 Fernandez M, Bermudez M, Boga JA, Vega-Naredo I, Coto-Montes A (2017) Overweight in elderly

818 people induces impaired autophagy in skeletal muscle. Free radical biology \& medicine 110:31-41.

819 doi:10.1016/j.freeradbiomed.2017.05.018

820 81. Wang L, Cano M, Handa JT (2014) p62 provides dual cytoprotection against oxidative stress in the 821 retinal pigment epithelium. Biochimica et biophysica acta 1843:1248-1258. doi:10.1016/j.bbamcr.2014.03.016

823 82. Santa-Maria I, Hernandez F, Moreno FJ, Avila J (2007) Taurine, an inducer for tau polymerization 824 and a weak inhibitor for amyloid-beta-peptide aggregation. Neuroscience letters 429:91-94. 825 doi:10.1016/j.neulet.2007.09.068

826 83. Richter-Landsberg C, Leyk J (2013) Inclusion body formation, macroautophagy, and the role of 827 HDAC6 in neurodegeneration. Acta neuropathologica 126:793-807. doi:10.1007/s00401-013-1158-x

828 84. Bauer NG, Richter-Landsberg C (2006) The dynamic instability of microtubules is required for 829 aggresome formation in oligodendroglial cells after proteolytic stress. Journal of molecular neuroscience 830 : MN 29:153-168. doi:10.1385/JMN:29:2:153

831 85. Gendron TF, Petrucelli L (2009) The role of tau in neurodegeneration. Molecular neurodegeneration 832 4:13. doi:10.1186/1750-1326-4-13

833 86. Schneider A, Mandelkow E (2008) Tau-based treatment strategies in neurodegenerative diseases. 834 Neurotherapeutics : the journal of the American Society for Experimental NeuroTherapeutics 5:443835 457. doi:10.1016/j.nurt.2008.05.006

836 87. Lin L, Huang QX, Yang SS, Chu J, Wang JZ, Tian Q (2013) Melatonin in Alzheimer's disease. 837 International journal of molecular sciences 14:14575-14593. doi:10.3390/ijms140714575 
88. Fellner L, Jellinger KA, Wenning GK, Stefanova N (2011) Glial dysfunction in the pathogenesis of

839 alpha-synucleinopathies: emerging concepts. Acta neuropathologica 121:675-693. doi:10.1007/s00401-

$840 \quad 011-0833-z$

841 89. Nelson PT, Alafuzoff I, Bigio EH, Bouras C, Braak H, Cairns NJ, Castellani RJ, Crain BJ, Davies

842 P, Del Tredici K, Duyckaerts C, Frosch MP, Haroutunian V, Hof PR, Hulette CM, Hyman BT, Iwatsubo

843 T, Jellinger KA, Jicha GA, Kovari E, Kukull WA, Leverenz JB, Love S, Mackenzie IR, Mann DM,

844 Masliah E, McKee AC, Montine TJ, Morris JC, Schneider JA, Sonnen JA, Thal DR, Trojanowski JQ,

845 Troncoso JC, Wisniewski T, Woltjer RL, Beach TG (2012) Correlation of Alzheimer disease

846 neuropathologic changes with cognitive status: a review of the literature. Journal of neuropathology and

847 experimental neurology 71:362-381. doi:10.1097/NEN.0b013e31825018f7

848 90. Xiao H, Run X, Cao X, Su Y, Sun Z, Tian C, Sun S, Liang Z (2013) Temperature control can abolish 849 anesthesia-induced tau hyperphosphorylation and partly reverse anesthesia-induced cognitive 850 impairment in old mice. Psychiatry and clinical neurosciences 67:493-500. doi:10.1111/pcn.12091

851 91. Zhao X, Sun X, Cai S, Ran D, Yan Y, Pei Z (2015) Role of alpha-synuclein in cognitive dysfunction: 852 Studies in Drosophila melanogaster. Molecular medicine reports 12:2683-2688. 853 doi:10.3892/mmr.2015.3763

854 92. Porter VR, Buxton WG, Fairbanks LA, Strickland T, O'Connor SM, Rosenberg-Thompson S, 855 Cummings JL (2003) Frequency and characteristics of anxiety among patients with Alzheimer's disease 856 and related dementias. The Journal of neuropsychiatry and clinical neurosciences 15:180-186. 857 doi:10.1176/jnp.15.2.180

858 93. Santos LE, Beckman D, Ferreira ST (2016) Microglial dysfunction connects depression and 859 Alzheimer's disease. Brain, behavior, and immunity 55:151-165. doi:10.1016/j.bbi.2015.11.011

860 94. Teri L, Ferretti LE, Gibbons LE, Logsdon RG, McCurry SM, Kukull WA, McCormick WC, Bowen 861 JD, Larson EB (1999) Anxiety of Alzheimer's disease: prevalence, and comorbidity. The journals of 862 gerontology Series A, Biological sciences and medical sciences 54:M348-352

863 95. Mack JM, Schamne MG, Sampaio TB, Pertile RA, Fernandes PA, Markus RP, Prediger RD (2016)

864 Melatoninergic System in Parkinson's Disease: From Neuroprotection to the Management of Motor and 
865 Nonmotor Symptoms. Oxidative medicine and cellular longevity 2016:3472032.

866 doi:10.1155/2016/3472032

867 96. Westling S, Ahren B, Traskman-Bendz L, Westrin A (2004) Low CSF leptin in female suicide 868 attempters with major depression. Journal of affective disorders 81:41-48. 869 doi:10.1016/j.jad.2003.07.002

870 97. Kraus T, Haack M, Schuld A, Hinze-Selch D, Koethe D, Pollmacher T (2002) Body weight, the 871 tumor necrosis factor system, and leptin production during treatment with mirtazapine or venlafaxine.

872 Pharmacopsychiatry 35:220-225. doi:10.1055/s-2002-36390

873 98. Ng RC, Cheng OY, Jian M, Kwan JS, Ho PW, Cheng KK, Yeung PK, Zhou LL, Hoo RL, Chung 874 SK, Xu A, Lam KS, Chan KH (2016) Chronic adiponectin deficiency leads to Alzheimer's disease-like 875 cognitive impairments and pathologies through AMPK inactivation and cerebral insulin resistance in 876 aged mice. Molecular neurodegeneration 11:71. doi:10.1186/s13024-016-0136-x

877 99. Wu B, Wei Y, Wang Y, Su T, Zhou L, Liu Y, He R (2015) Gavage of D-Ribose induces Abeta-like 878 deposits, Tau hyperphosphorylation as well as memory loss and anxiety-like behavior in mice. 879 Oncotarget 6:34128-34142. doi:10.18632/oncotarget.6021

880 100. Guardiola-Lemaitre B, Lenegre A, Porsolt RD (1992) Combined effects of diazepam and melatonin 881 in two tests for anxiolytic activity in the mouse. Pharmacology, biochemistry, and behavior 41:405-408 882 


\section{Table footnotes}

885 Table 1 The data are shown as the mean \pm SD, and were calculated from at least three separate 886 experiments performed in triplicate. WC, wild-type; WM, wild-type plus melatonin; ObC, ob/ob; ObM, $887 \mathrm{ob} / \mathrm{ob}$ plus melatonin. \# wild-type vs. ob/ob and * melatonin-treated animals vs. melatonin-untreated animals. $\# p<0.05, * p<0.05, \# \# p<0.01, * * p<0.01, \# \# p<0.001, * * * p<0.001$.

\section{$890 \quad$ Figure captions}

891 Fig. 1 Oxidative damage and antioxidant defense in the brain of wild-type and ob/ob mice. (a) Protein 892 damage was expressed as nmol carbonylated protein/mg protein. (b) Total antioxidant activity (TAA) 893 was expressed as equivalents of $\mathrm{mg}$ equivalents Trolox/mg protein. (c) Superoxide dismutase (SOD) 894 activity was expressed as SOD units/mg protein. (d) Catalase (CAT) activity was expressed as $\mu$ mol $895 \mathrm{H}_{2} \mathrm{O}_{2} / \mathrm{mg}$ protein*min. (e) Glutathione peroxidase (GPx) activity was expressed as $\mu \mathrm{mol} \mathrm{NADPH} / \mathrm{mg}$ 896 protein*min. (f) Glutathione reductase (GR) activity was expressed as $\mu$ mol NADPH/mg protein*min. The data are presented as the mean values \pm standard deviations (SD) of the means. All data presented

898 representative data obtained from at least three separate experiments. WC, wild-type; WM, wild-type 899 plus melatonin; ObC, ob/ob; ObM, ob/ob plus melatonin. \# wild-type vs. ob/ob and * melatonin-treated animals vs. untreated animals. $\# p<0.05,{ }^{*} p<0.05, \# \# p<0.01,{ }^{* *} p<0.01, \# \# p<0.001,{ }^{* * *} p<0.001$.

Fig. 2 Inflammatory markers from the brain of wild-type and ob/ob mice. Tumour necrosis factor $\alpha$ (TNF- $\alpha$ ) and interleukin 6 (IL-6) levels were expressed as $\mathrm{pg} / \mathrm{mg}$ protein. The data are presented as the mean values \pm standard deviations (SD) of the means. All data presented representative data obtained from at least three separate experiments. WC, wild-type; WM, wild-type plus melatonin; ObC, ob/ob;

906 ObM, ob/ob plus melatonin. \# wild-type vs. ob/ob and * melatonin-treated animals vs. untreated animals. $\# p<0.05,{ }^{*} p<0.05, \# \# p<0.01, * * p<0.01, \# \# p<0.001, * * * p<0.001$.

Fig. 3 Endoplasmic reticulum (ER) stress markers in the brain of wild-type and ob/ob mice. (a) Bar chart showing the semiquantitative optical density (arbitrary units of blots bands) of inositol-requiring 
911 enzyme $1 \alpha$ (IRE1 $\alpha)$, phosphorylated-eukaryotic initiation factor $2 \alpha$ (p-eIF2 $\alpha$ ) and activating

912 transcription factor-6 $\alpha$ (ATF-6 $\alpha$ ) from western blot normalized to ponceau and expressed as percent

913 change from the WC sample. (b) Bar chart showing the semiquantitative optical density (arbitrary units

914 of blots bands) of heat shock cognate $71 \mathrm{kDa}$ (hsc70) protein from sodium dodecyl sulfate-

915 polyacrylamide gel image of protein extracts of the brain obtained from analysis by matrix-assisted laser

916 desorption/ionization-time of flight (MALDI-TOF/TOF) mass spectrometry. The results were expressed

917 as percent change from the WC sample. The data are presented as the mean values \pm standard deviations

918 (SD) of the means. All data presented representative data obtained from at least three separate

919 experiments. WC, wild-type; WM, wild-type plus melatonin; ObC, ob/ob; ObM, ob/ob plus melatonin.

920 \# wild-type vs. ob/ob and * melatonin-treated animals vs. untreated animals. $\# p<0.05, * p<0.05$,

$921 \# \# p<0.01, * * p<0.01, \# \# p<0.001,{ }^{* * *} p<0.001$.

922

923 Fig. 4 Ubiquitin-Proteasome system in the brain of wild-type and ob/ob mice. (a) 20S proteasome 924 activity is expressed as arbitrary fluorescence $\mu \mathrm{M} \mathrm{AMC} / \mathrm{mg}$ protein. (b) Bar chart showing the 925 semiquantitative optical density (arbitrary units of blots bands) of ubiquitin from western blot 926 normalized to ponceau and expressed as percent change from the WC sample. The data are presented as 927 the mean values \pm standard deviations (SD) of the means. All data presented representative data obtained 928 from at least three separate experiments. WC, wild-type; WM, wild-type plus melatonin; ObC, ob/ob; 929 ObM, ob/ob plus melatonin. \# wild-type vs. ob/ob and * melatonin-treated animals vs. untreated 930 animals. $\# p<0.05,{ }^{*} p<0.05, \# \# p<0.01,{ }^{* *} p<0.01, \# \# p<0.001, * * * p<0.001$.

932 Fig. 5 Autophagy markers in the brain of wild-type and ob/ob mice. Bar chart showing the 933 semiquantitative optical density (arbitrary units of blots bands) of lysosome associated membrane 934 protein type 2A (LAMP2A), Beclin-1, microtubule-associated protein 1 light chain 3 I (LC3-I), 935 microtubule-associated protein 1 light chain 3 II (LC3-II) and p62 from western blot normalized to 936 ponceau and expressed as percent change from the WC sample. The data are presented as the mean 937 values \pm standard deviations (SD) of the means. All data presented representative data obtained from at 938 least three separate experiments. WC, wild-type; WM, wild-type plus melatonin; ObC, ob/ob; ObM, 
ob/ob plus melatonin. \# wild-type vs. ob/ob and $*$ melatonin-treated animals vs. untreated animals.

$\# p<0.05,{ }^{*} p<0.05, \# \# p<0.01, * * p<0.01, \# \# \# p<0.001, * * * p<0.001$.

942 Fig. 6 Cytoskeleton markers in the brain of wild-type and ob/ob mice. Bar chart showing the semiquantitative optical density (arbitrary units of blots bands) of $\beta$-actin, $\alpha$-tubulin and vimentin from

944 western blot normalized to ponceau and expressed as percent change from the WC sample. The data 945 are presented as the mean values \pm standard deviations (SD) of the means. All data presented 946 representative data obtained from at least three separate experiments. WC, wild-type; WM, wild-type 947 plus melatonin; ObC, ob/ob; ObM, ob/ob plus melatonin. \# wild-type vs. ob/ob and * melatonin-treated 948 animals vs. untreated animals. $\# p<0.05,{ }^{*} p<0.05, \# \# p<0.01,{ }^{*} * p<0.01, \# \# \#<0.001,{ }^{*} * * p<0.001$.

Fig. 7 Neurodegeneration markers in the brain of wild-type and ob/ob mice. (a) Bar chart showing the semiquantitative optical density (arbitrary units of blots bands) of $\beta$-amyloid and $\alpha$-synuclein from western blot normalized to ponceau and expressed as percent change from the WC sample. (b) Bar chart showing the semiquantitative optical density (arbitrary units of blots bands) of Tau $\mathrm{pS}^{199}$, Tau $\mathrm{pT}^{205}$, Tau $\mathrm{pS}^{396}$ and Tau $\mathrm{pS}^{404}$ from western blot normalized to ponceau and expressed as percent change from the WC sample. The data are presented as the mean values \pm standard deviations $(\mathrm{SD})$ of the means. All data presented representative data obtained from at least three separate experiments. WC, wild-type; WM, wild-type plus melatonin; $\mathrm{ObC}$, ob/ob; ObM, ob/ob plus melatonin. \# wild-type vs. ob/ob and * melatonin-treated animals vs. untreated animals. $\# p<0.05,{ }^{*} p<0.05, \# \# p<0.01,{ }^{* *} p<0.01, \# \# \# p<0.001$, $* * * p<0.001$

961 Fig. 8 Evaluation of stress-induced behavior in the brain of wild-type and ob/ob mice. Bar chart showing the (a) immobility and the (b) mobility latency time percents in Porsolt Swim Test (PST) for last 4 min

963 of the test. The data are presented as the mean values \pm standard deviations (SD) of the means. All data

964 presented representative data obtained from at least three separate experiments. WC, wild-type; WM, 965 wild-type plus melatonin; ObC, ob/ob; ObM, ob/ob plus melatonin. \# wild-type vs. ob/ob and * 
966 melatonin-treated animals vs. untreated animals. $\# p<0.05,{ }^{*} p<0.05, \# \# p<0.01,{ }^{* *} p<0.01, \# \# \# p<0.001$, $967 \quad * * * p<0.001$. 


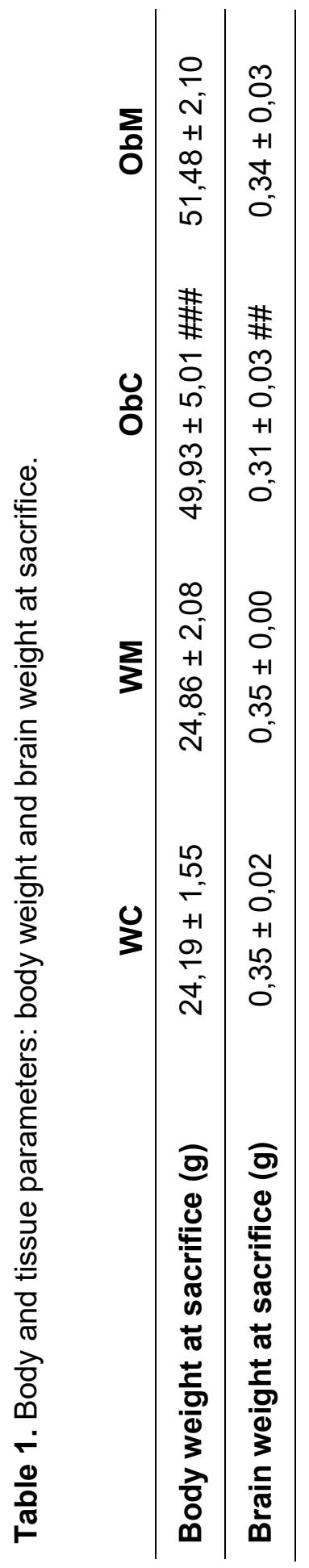




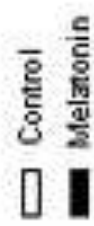

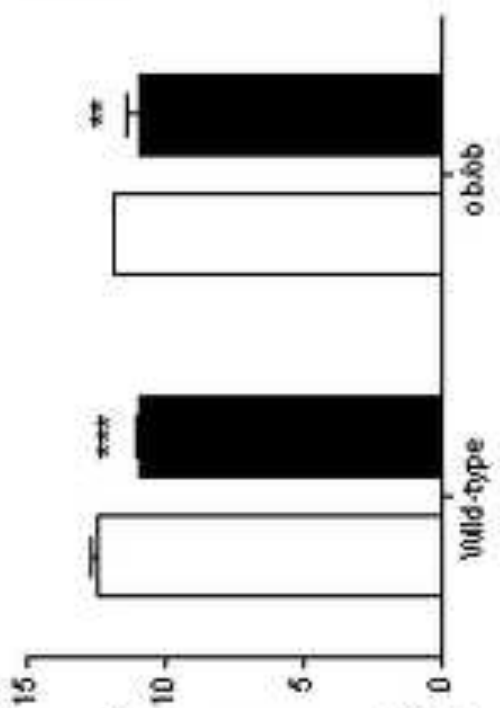

(u!a Loud Bupoojos squapeunba tu) ㅇ Kan!pe juepixonue utpo 1

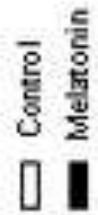

$\approx$

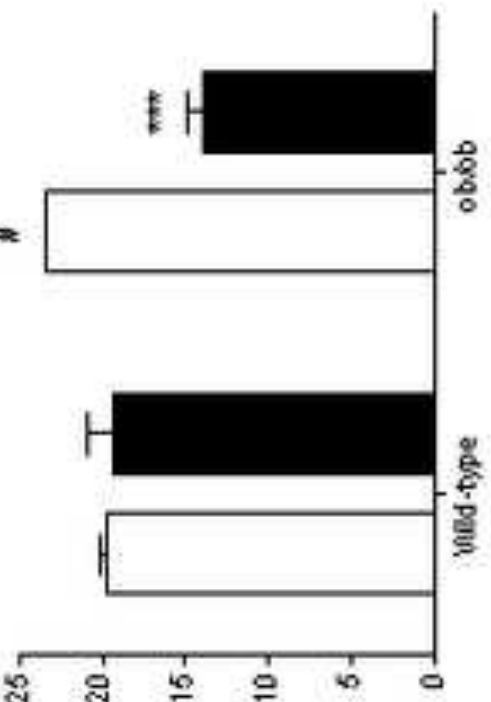
(uishoud buynuo ques uịsoud jouv) a6euep esyepixo uịyo Jd
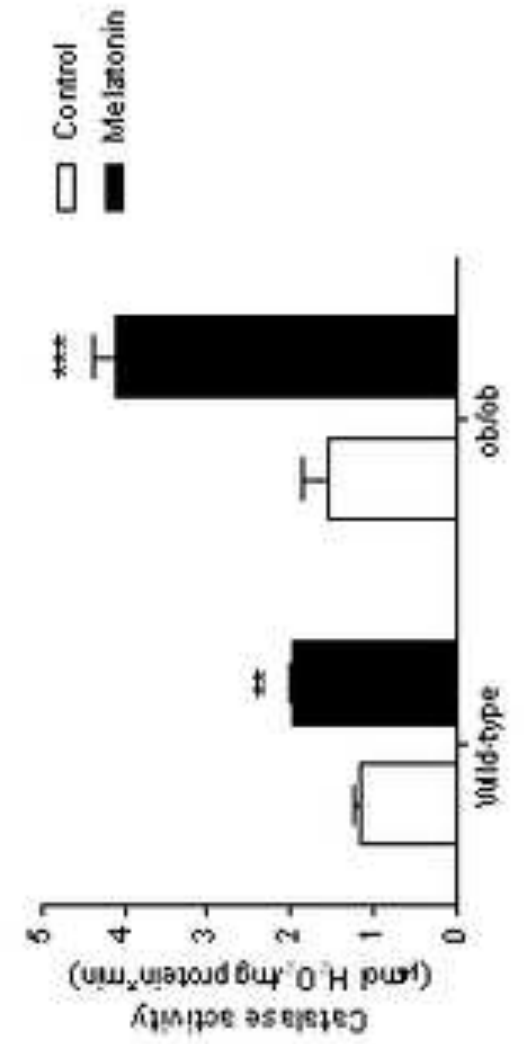

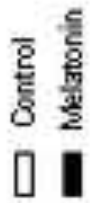

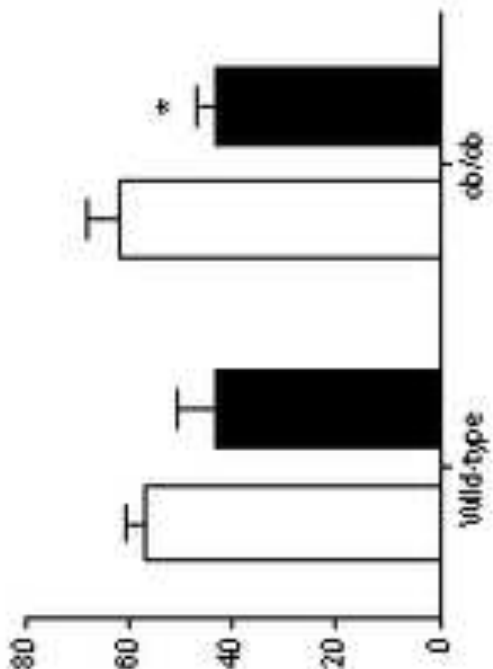

(urenoud buysunn)

A unı!pe osepnus!p ap! you adns
들
总
$8 \frac{8}{2}$
01

春

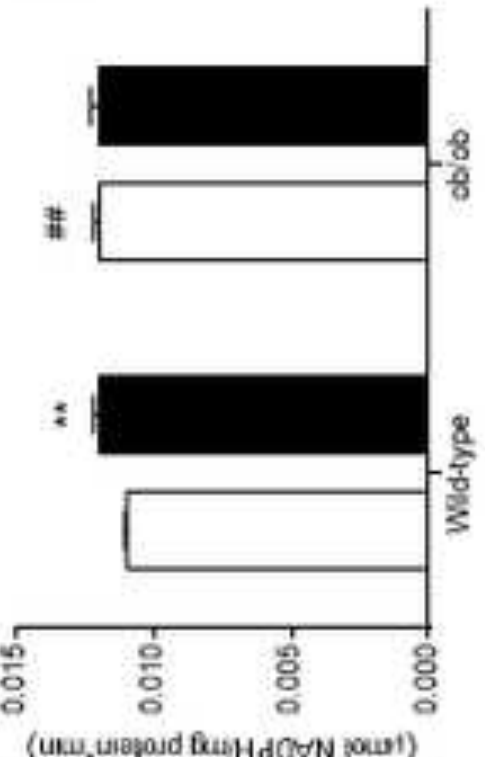

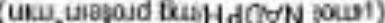

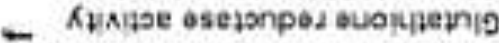
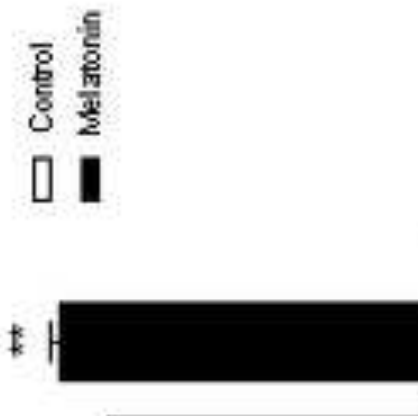

$7 t$

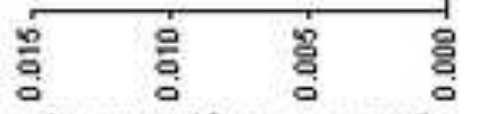

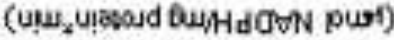

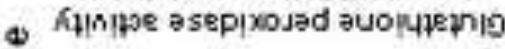



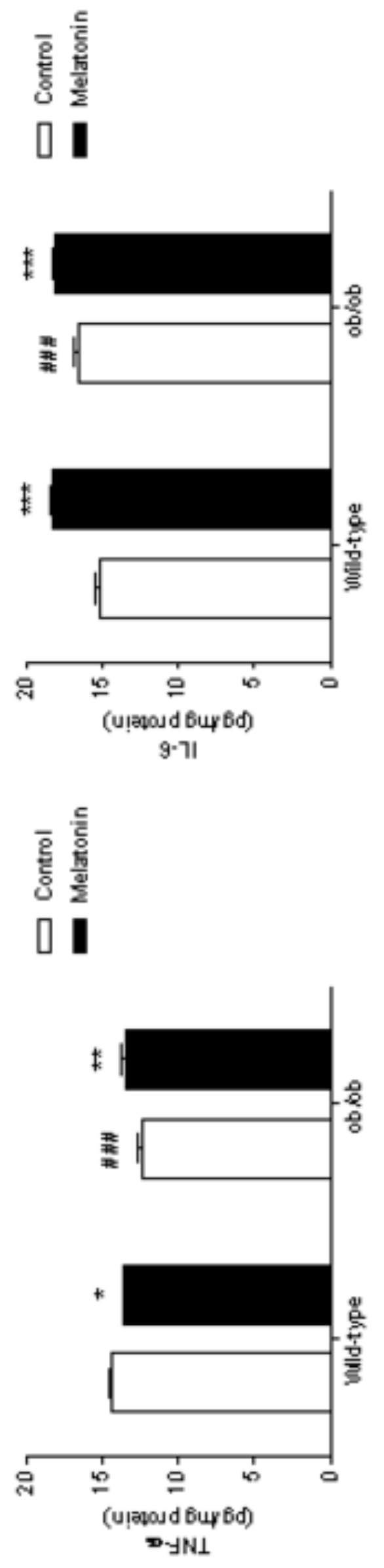

N
$\stackrel{\underline{\nu}}{丂}$
믄 

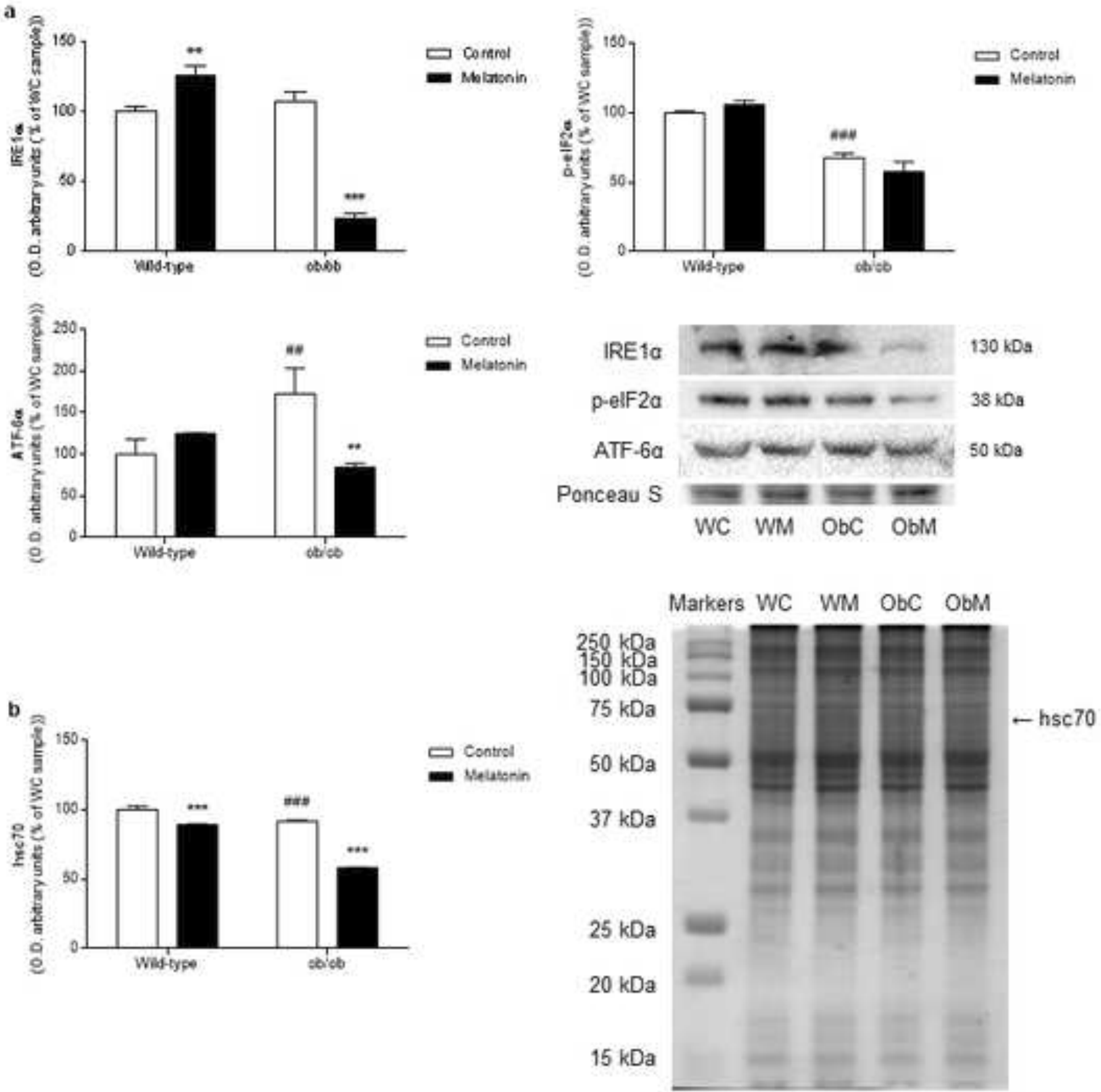


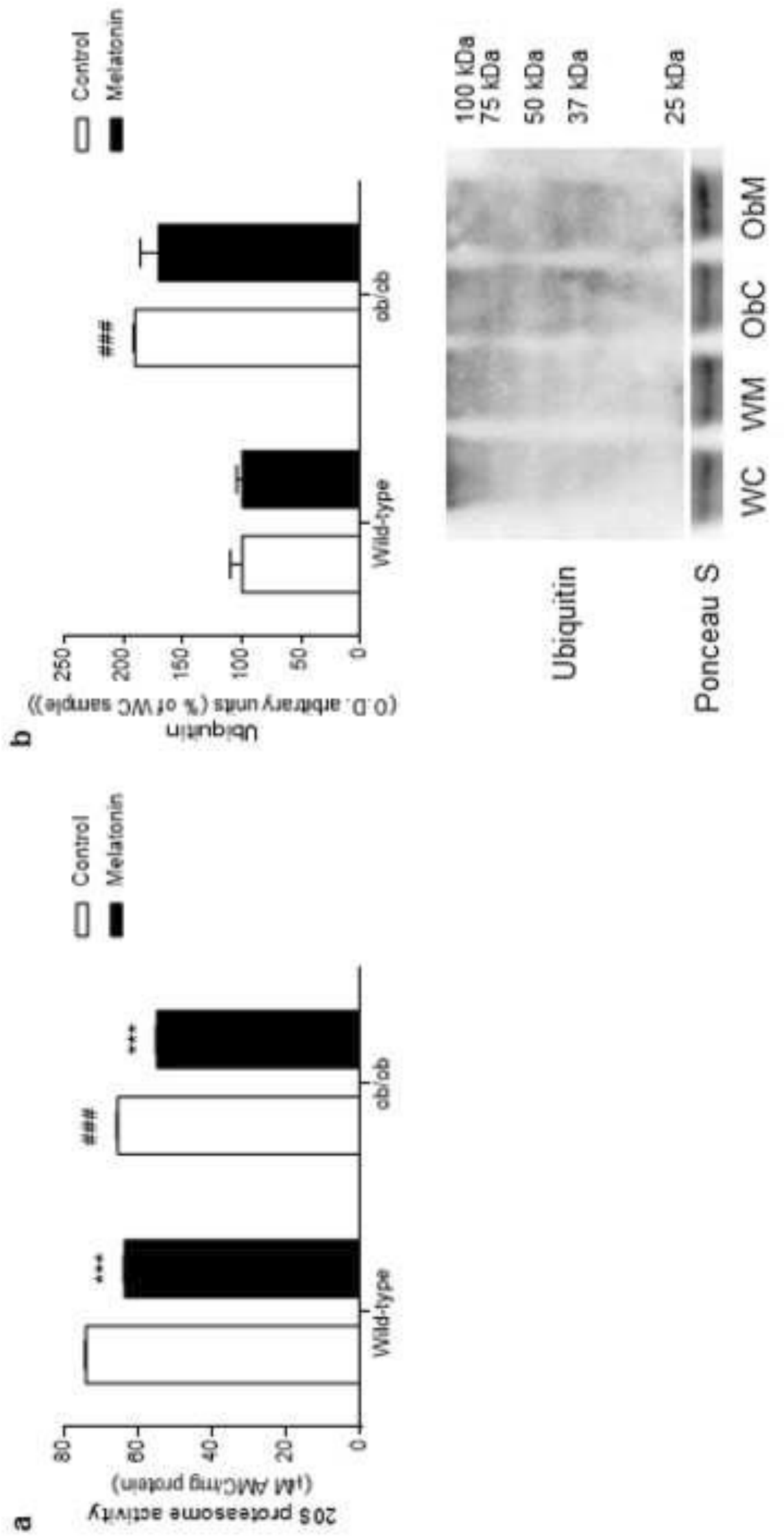

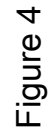



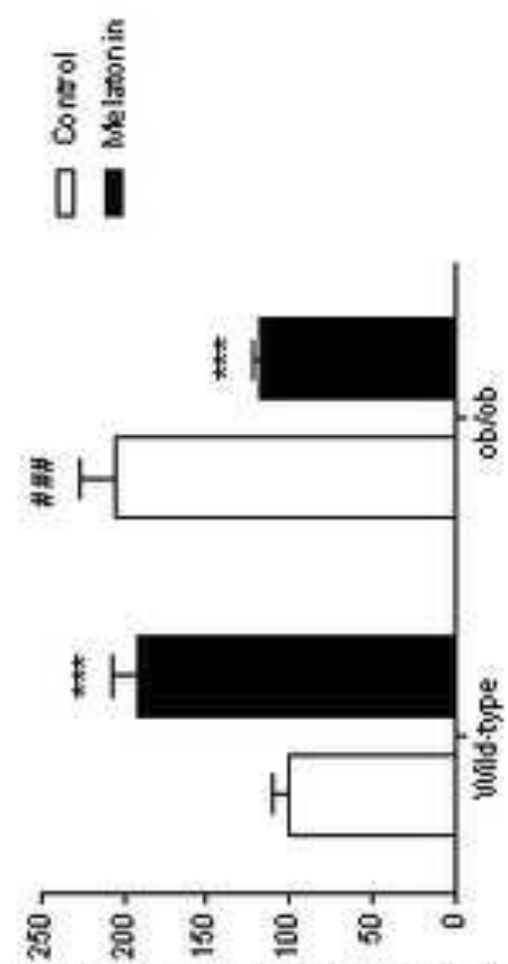

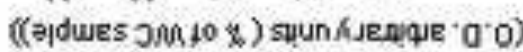
เ. บ!!peg
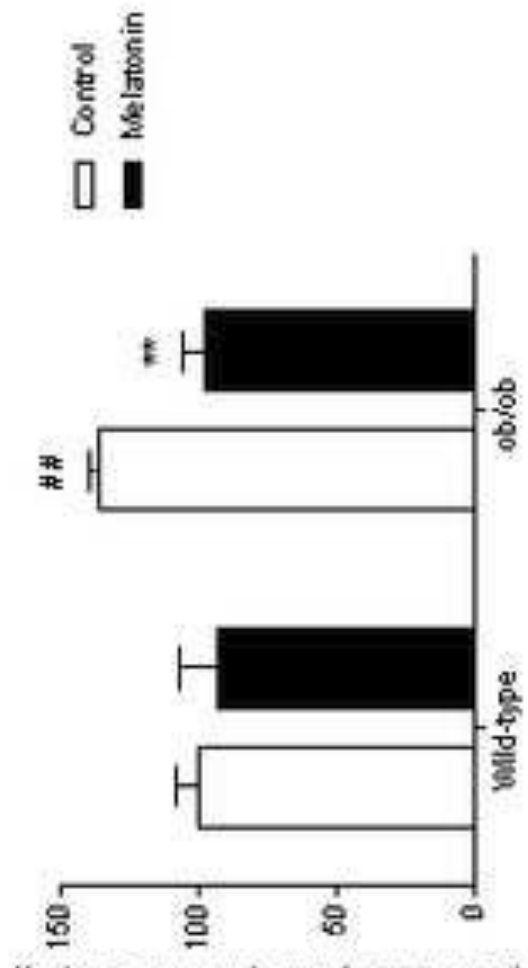

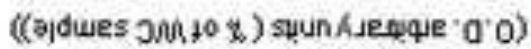
ชटdन का

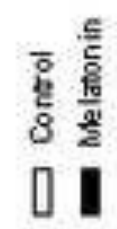

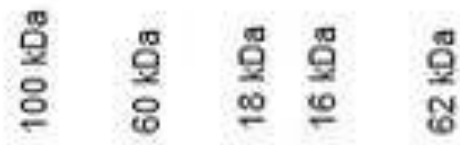
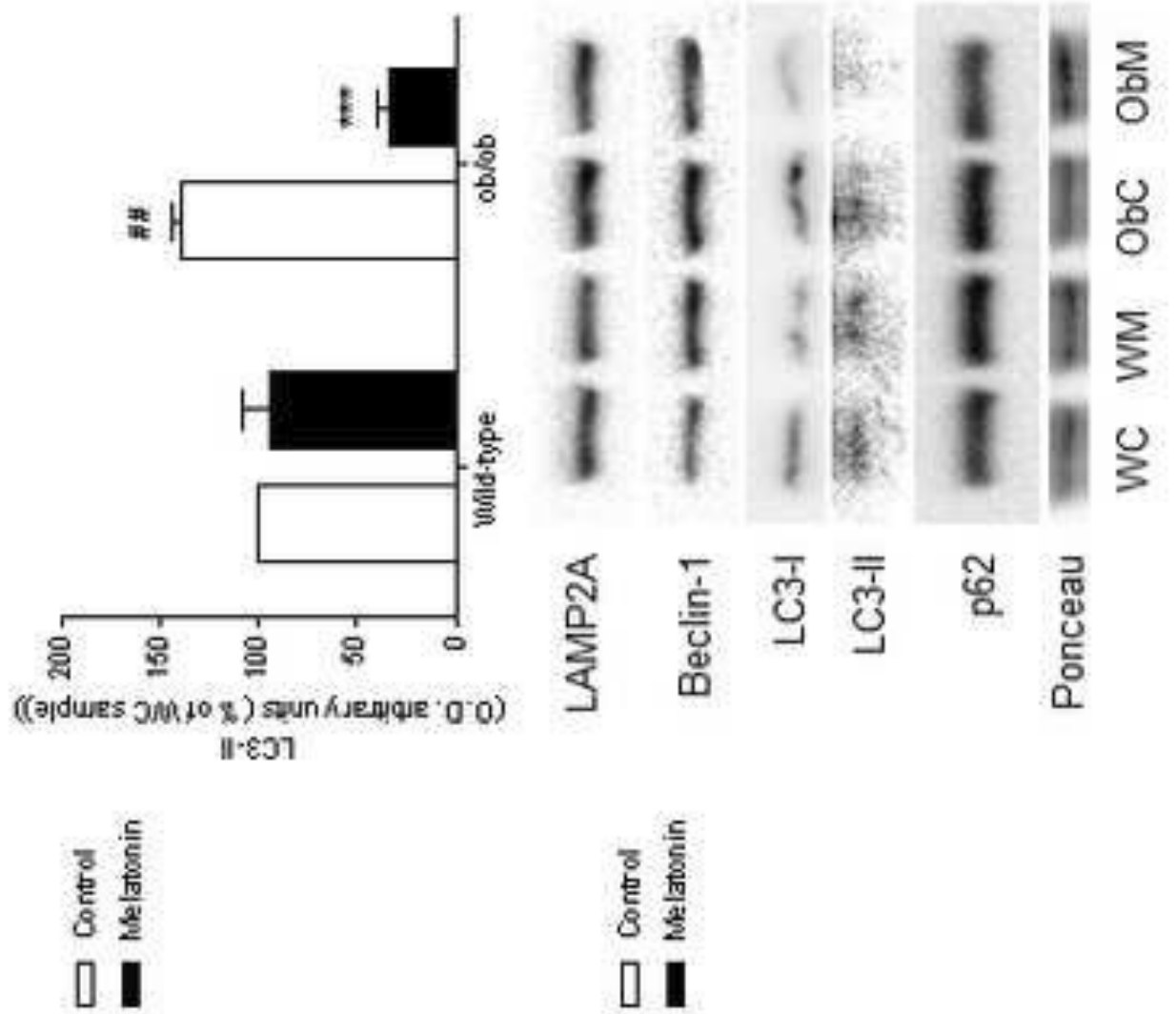

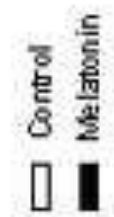

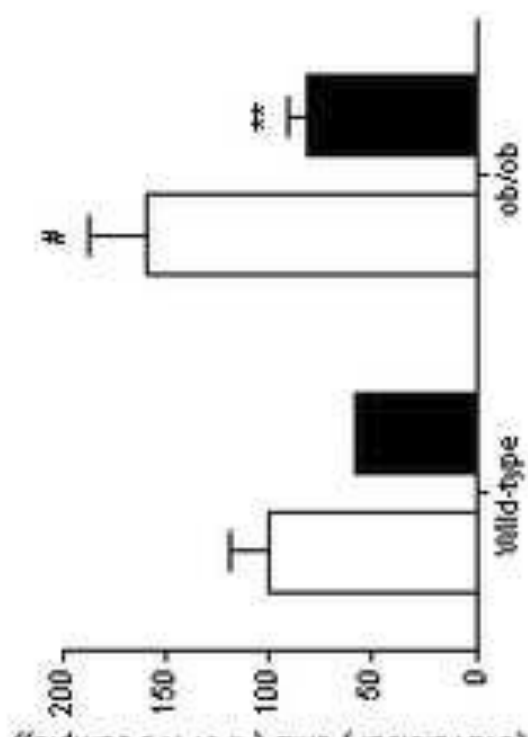

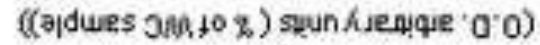
$1 \cdot 807$

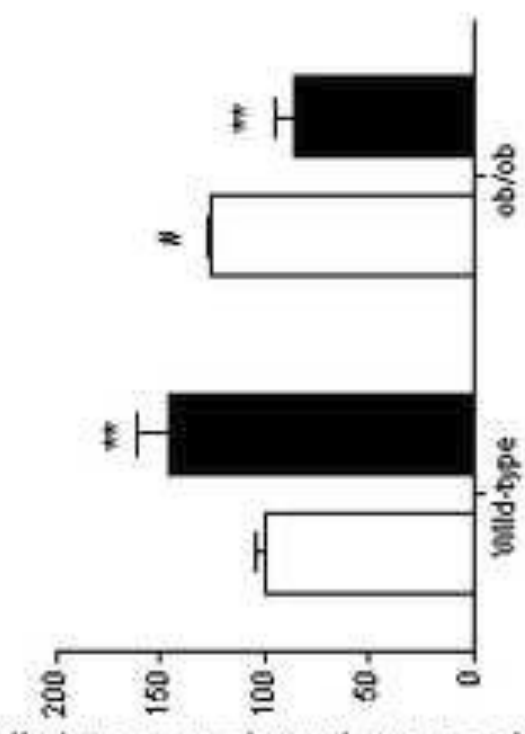

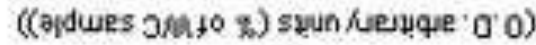
$z 9 d$ 


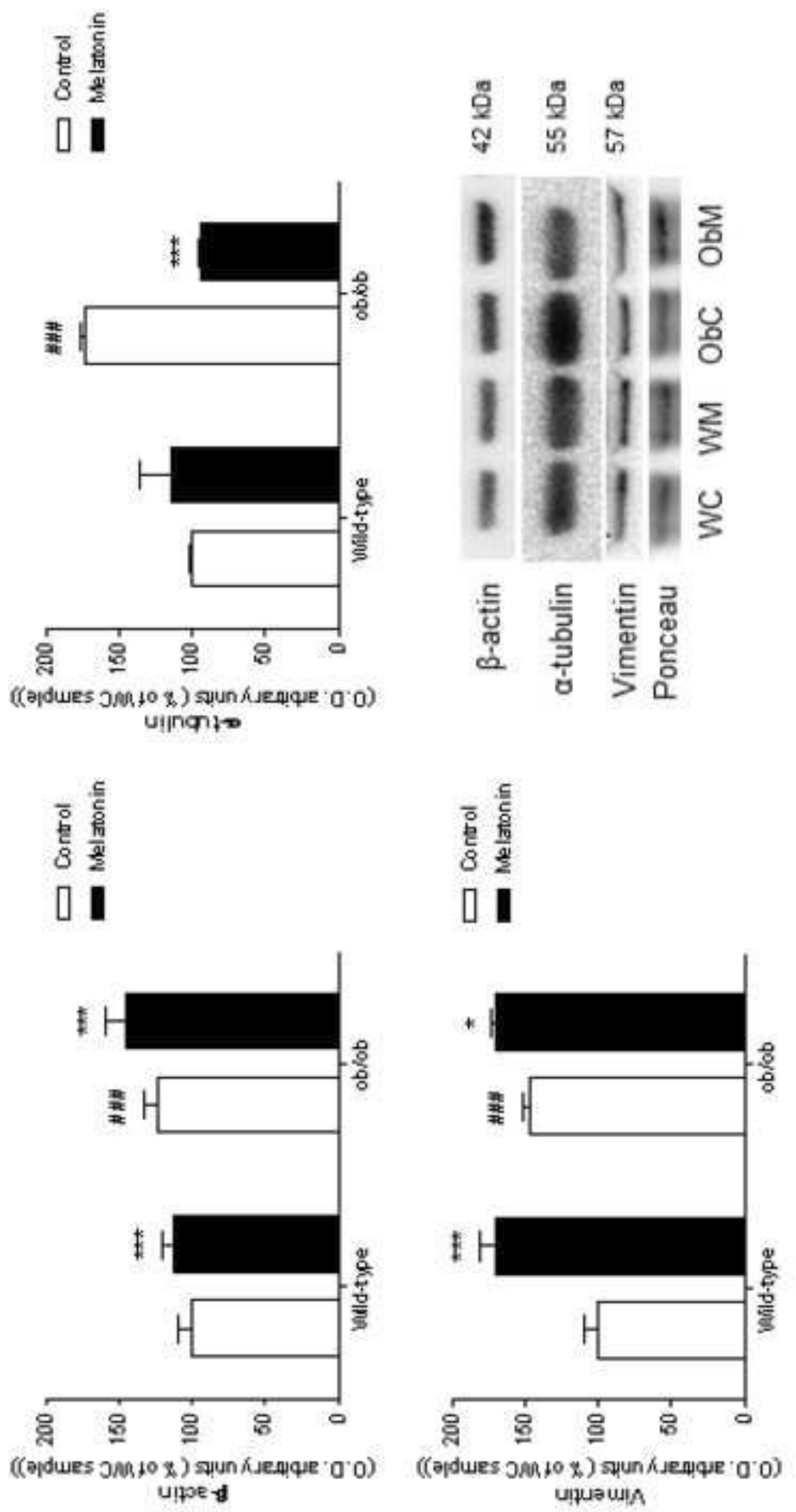

0
ఖ
믐
은 

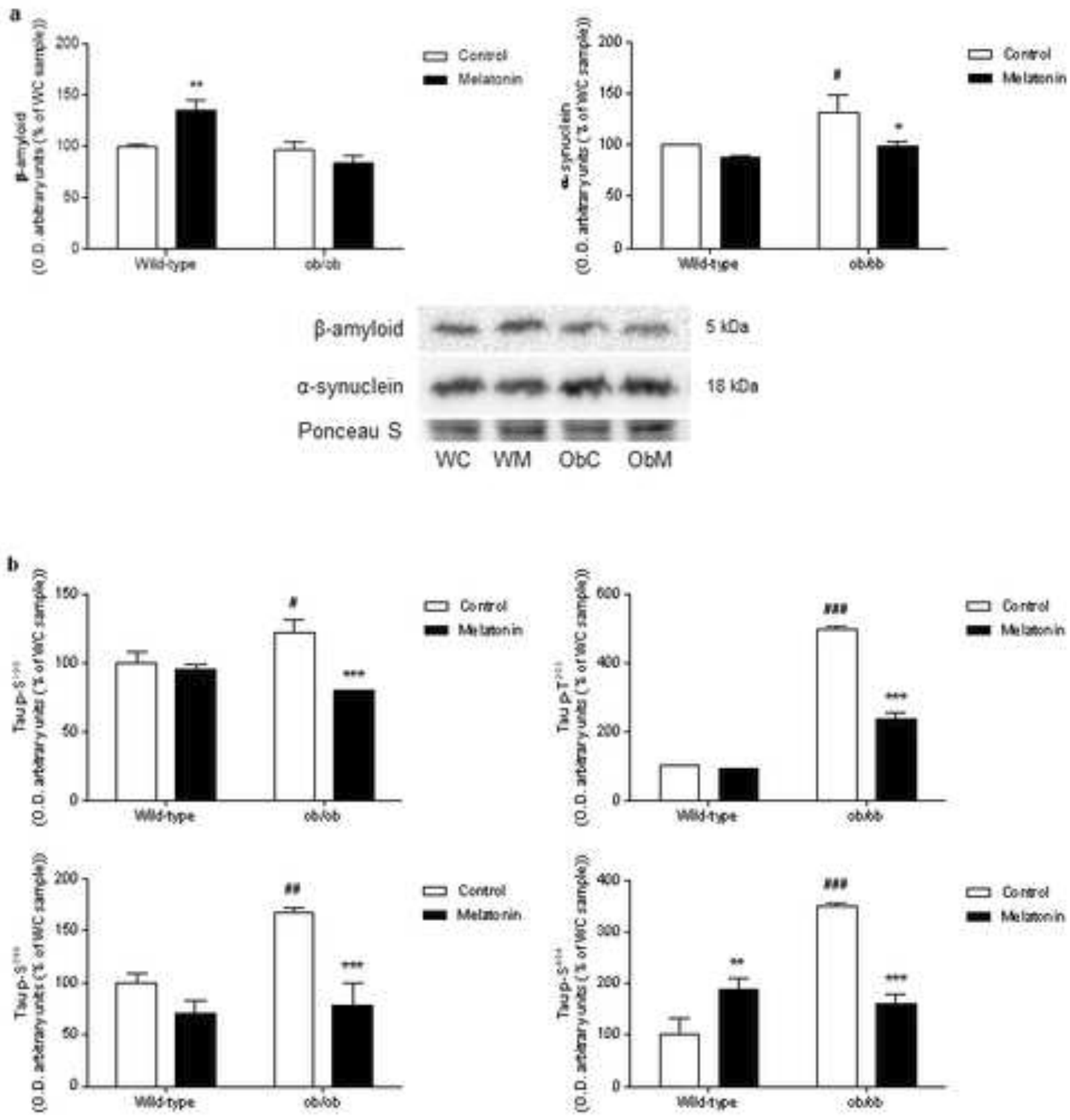

Tau p-S s9 $^{199}$

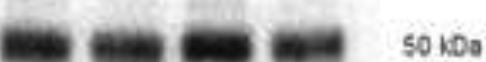

Tau p.TNS

$50 \mathrm{KDa}$

Tau p-S ${ }^{360}$

$\$ 0$ KDa

Tau p. $\mathbf{S}^{404}$

$50 \mathrm{kDa}$

Ponceau S

WC WM ObC ObM 


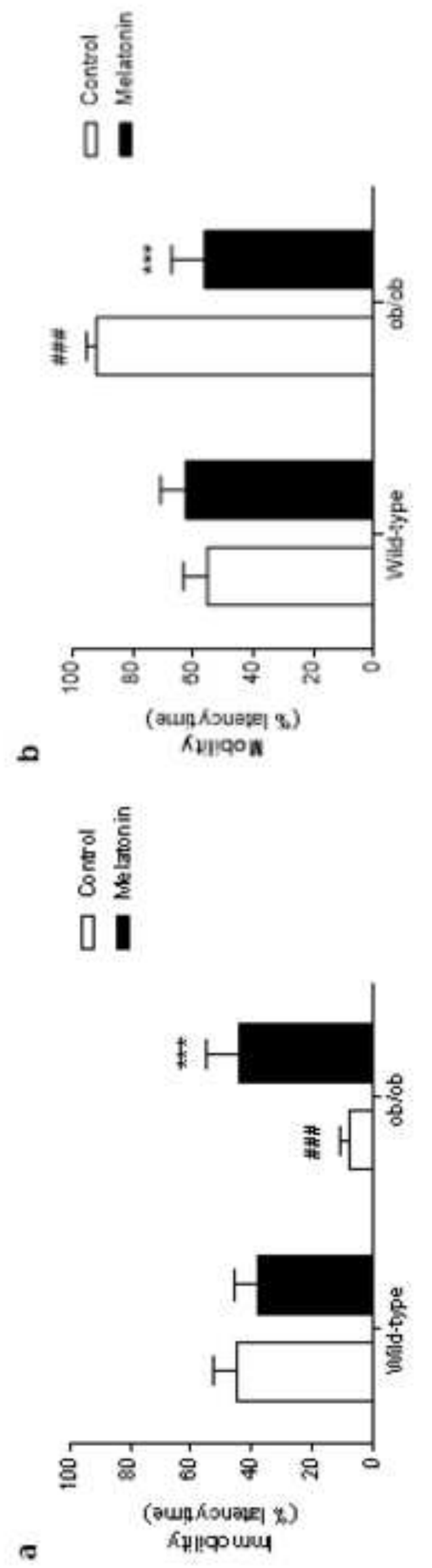

$\infty$
$\stackrel{0}{\frac{1}{5}}$
믄 